\title{
Current progress on understanding the impacts of mercury on human health
}

Eunhee $\mathrm{Ha}^{1}$, Niladri Basu², Stephan Bose-O’Reilly ${ }^{3,4}$, José G. Dórea ${ }^{5}$, Emeir McSorley ${ }^{6}$, Mineshi Sakamoto ${ }^{7}$, Hing Man Chan ${ }^{8 *}$

${ }^{1}$ Ewha Womans University, College of Medicine, Department of Preventive Medicine, Korea

${ }^{2}$ Faculty of Agricultural and Environmental Sciences, McGill University, Canada

${ }^{3}$ University Hospital Munich, Institute and Outpatient Clinic for Occupational, Social and

Environmental Medicine, WHO Collaborating Centre for Occupational Health, Germany

${ }^{4}$ University for Health Sciences, Medical Informatics and Technology (UMIT), Department of Public Health, Health Services Research and Health Technology Assessment, Austria

${ }^{5}$ Department of Nutrition, University of Brasília, Brasília, Brazil

${ }^{6}$ Northern Ireland Centre for Food and Health, Ulster University, United Kingdom

${ }^{7}$ Department of Epidemiology, National Institute for Minamata Disease

${ }^{8}$ Department of Biology, University of Ottawa, Canada

* Corresponding author:

Dr. Laurie Hing Man Chan

Tel: (613) 562-5800 x7116

Fax: (613) 562-5385

Email: laurie.chan@uottawa.ca 


\begin{abstract}
Mercury pollution and its impacts on human health are global concern. The authors of this paper were members of the Plenary Panel on Human Health in the $12^{\text {th }}$ International Conference on Mercury as a Global Pollutant held in Korea in June 2015. The Panel was asked by the conference organizers to address two questions: what is the current understanding of the impacts of mercury exposure on human health and what information is needed to evaluate the effectiveness of the Minamata Convention in lowering exposure and preventing adverse effects. The authors conducted a critical review of the literature published since January 2012 and discussed the current state-of-knowledge in the following areas: environmental exposure and/or risk assessment; kinetics and biomonitoring; effects on children development; effects on adult general populations; effects on artisanal and small-scale gold miners (ASGM); effects on dental workers; risk of ethylmercury in Thimerosal-containing vaccines; interactions with nutrients; genetic determinants and; risk communication and management. Knowledge gaps in each area were identified and recommendations for future research were made. The Panel concluded that more knowledge synthesis effort is needed to translate the research results into management tools for health professionals and policy makers.
\end{abstract}

Key words: Critical Review; Environmental Exposure; Environmental Pollutants; Humans; Mercury; Methylmercury; Toxicity; Health; Advisory 


\section{Introduction}

Mercury (Hg) is a global pollutant that affects human and ecosystem health (UNEP 2013). The awareness of health effects of Hg pollution began since the 1950s when chemical waste was released into the nearby sea by the Chisso Corporation in Minamata, Japan. The waste led to the accumulation of the more bioavailable form of $\mathrm{Hg}$, i.e. methylmercury (MeHg) in fish, and consequent devastating thousands of local populations who had consumed the fish as their main food source (Kurland et al. 1960). It is well documented that prenatal or postnatal exposure to MeHg can produce adverse neurological impacts in adults and children, now known as Minamata Disease (Harada 1995). These patients with chronic Hg poisoning continue to complain of distal paresthesias of the extremities and the lips even 30 years after cessation of exposure to MeHg (Ekino et al. 2007). Moreover, more recent evidence showed that even general population exposed to MeHg in Minamata who were not certified Minamata Disease patients showed increased risk of psychiatric symptoms (e.g., impairment of intelligence and mood and behavioral dysfunction) (Yorifuji et al. 2011). With increasing awareness of environmental stewardship, an incidence of acute Hg poisoning from industrial pollution like Minamata has become rare. However, the scale of chronic exposure to a lower dose of $\mathrm{Hg}$ as a result of global pollution or occupational hazard has grown. For example, the Food and Agriculture Organization (FAO)/World Health Organization (WHO) identified that hundreds of millions of peoples worldwide who rely on fish as their major source of protein in their diet are at risk of increased exposure to MeHg (FAO/WHO 2011). Artisanal and small-scale gold mining is another major contributor to mercury consumption and emissions into the environment affecting millions of people particularly in low- and middle-income countries (Veiga et al. 2006). 
These growing concerns have led to the initiation of numerous international efforts to address the issues. For example, the United Nations Environment Programme (UNEP) has implemented a number of global projects that aimed at decreasing human health and environmental risk from the release of $\mathrm{Hg}$, as well as improving the understanding of international $\mathrm{Hg}$ emissions and their transport and fate (UNEP, 2013a). Most significantly, an international treaty (Minimata Convention on Mercury) was signed in October 2013 to control the global release of Hg to the environment (UNEP, 2013b). The objective of the Minamata Convention, as indicated in Article 1 , is "to protect the human health and the environment from anthropogenic emissions and releases of mercury and mercury compounds” (UNEP, 2013b). The Convention recognizes that anthropogenic emissions are a serious threat to human and environmental health and each signing nation will make a commitment to reduce the emission and use of $\mathrm{Hg}$ to protect human and environmental health. By the end of 2015, the Minamata Convention has been signed by 128 countries and ratified by 20 countries. It will go into effect after 50 countries have deposited their instruments of ratification, acceptance, approval, or accession that is expected to be in 2017. Article 16 of the Convention stated the concern on human health aspects. It encourages states to promote strategies to: 1) identify all the population affected by mercury pollution; 2) adopt health guidelines regulating mercury exposure; and 3) provide education about dangers of mercury exposure. Countries should provide appropriate health-care for treatment and care for people who are already exposed to mercury compounds. It is clear that more scientific knowledge is needed to fully understand effects of $\mathrm{Hg}$ emission reduction on environmental concentrations and identify other factors leading to reduced human exposure and resulting in prevention of adverse outcome. Moreover, integration of science with national and international 
policy efforts is needed to target efforts in the implementation of the intervention and evaluate the effectiveness of the Convention on improving health.

The authors of this paper were invited by the organizing committee of the $12^{\text {th }}$ International Conference on Mercury as a Global Pollutant held in Korea in June 2015 to be members of the Plenary Panel on Human Health. The Panel was challenged to prepare presentations to address two questions: what is the current understanding of the impacts of mercury exposure on human health and what information is needed to evaluate the effectiveness of the Minamata Convention in lowering exposure and preventing adverse effects. This review paper is prepared based on the presented materials and discussions at the Conference. In addition, a systemic review of the literature was conducted to assured all the most recent publications are included in our attempt to address these questions. 


\section{Methods}

A literature search was conducted in OVID Medline (January 2012-present) and Toxline (January 2012-present). The search strategy combined terms for mercury, methylmercury, human, and health. The rationale for the choice of inclusion period was based on the publication of the latest review paper of this nature by Driscoll et al. (2013) that cited bibliography published until the end of 2011. The included papers were grouped into the following 10 major areas: environmental exposure and/or risk assessment; kinetics and biomonitoring; effects on children development; effects on adult general populations; effects on artisanal and small-scale gold miners; effects on dental workers; risk of vaccination; interactions with nutrients; genetic determinants and; risk communication and management. Selected publications were included in this critical review in the context of addressing the two questions posed to the Panel (Figure 1).

Total articles identified in electronic search : 815 papers

Search engines : OVID Medline and Toxline (January 2012-present)

Combined key words:mercury, methylmercury, human, and health

Addressing the two questions posed to the Panel : 766 papers

- the current understanding of the impacts of mercury exposure on human health - information needed to evaluate the effectiveness of the Minamata Convention

\section{Exclusion criteria papers}

$\Rightarrow$ - primarily reported results in environmental matrices(121)

- bench studies limited implications on human health ( 65 )

- studies on other species (66)

\section{Final relevant papers: 514}

Grouped 10 major areas: environmental exposure and/or risk assessment; kinetics and biomonitoring; effects on children development; effects on adult general populations; effects on artisanal and small-scale gold miners; effects on dental workers; risk of vaccination; interactions with nutrients; genetic determinants and; risk communication and management.

Figure 1. Flow chart of literature search for the impacts of mercury on human health 


\section{Results}

The literature search found a total of 815 papers published between Jan 1, 2012 to present. A screening found that 514 are relevant (Table 1). The others primarily reported results in environmental matrices, bench-based studies that have limited immediate implications on human health, or studies on other species.

Table 1. Results of the literature search of papers published related to $\mathrm{Hg}$ health effects.

Areas

Review papers

Environmental exposure and risk assessment

Kinetics and Biomarkers

Effects on children development Effects on fish consuming adults

Health hazards of artisanal and small-scale gold

mining

Effects of Dental Amalgam

Effects of $\mathrm{Hg}$ in Thimerosal-containing vaccines

Nutrient interactions

Genetic Factors

Risk communication and Policy

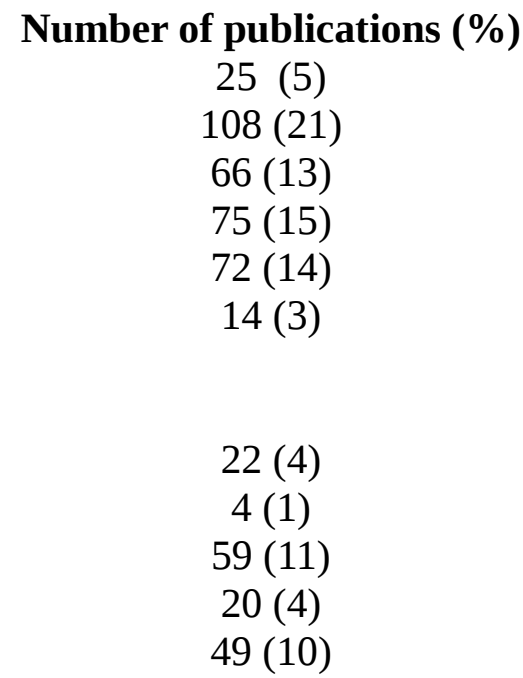

$514(100)$

The relative number or percentages of publications in the 10 different areas of $\mathrm{Hg}$ research may reflect the recent research focus. It is not surprising that the highest number of papers (21\%) was on environmental monitoring and exposure assessment. This is the first step of hazard identification in many regions around the world. There was almost an equal number of studies reporting effects of $\mathrm{Hg}$ on maternal-child health (15\%) and adult fish consuming populations (14\%). There were $11 \%$ of papers reporting results on the interactions between nutrients and $\mathrm{Hg}$ effects. The risk of Hg exposure on artisanal and small-scale gold miners (3\%) and effects of dental amalgam (4\%) have been intensive areas of research. The potential risk of Thimerosal- 
containing vaccines (1\%) remains to be a concern and studied. Genetic polymorphisms (4\%) have been identified to be important modifiers or confounding factors affecting the toxicokinetics and effects of $\mathrm{Hg}$. Almost $10 \%$ of the papers are on risk communications and policy, again showing the growing challenge among public health professionals to educate the public on the complex issues of risks and benefits. The following sections will discuss the state of the knowledge and knowledge gaps in each of these areas.

\section{Discussion}

There were 25 review papers published during that period. The relatively high number of review papers (almost 5\%) of the publications probably reflected the increase scientific interests in the Hg research and the response among of the environmental health scientists to the call from the national and international agencies on the need for scientific evidence support for the signing of the Minamata Convention. We highlighted 4 papers of review papers below. Rice et al. (2014) reviewed the systemic pathophysiology of individual organ systems including cellular, cardiovascular, hematological, pulmonary, renal, immunological, neurological, endocrine, reproductive, and embryonic toxicological effects. The review by Syversen \& Kaur (2012) attempted to address the long time " mysteries" of methylmercury neurotoxicology related to the cellular selectivity and the delayed onset of symptoms and presented some suggestions towards explaining these observations. Bernhoft (2012) focused his review on the diagnosis of $\mathrm{Hg}$ clinical toxicity and therapeutic treatments. Sheehan et al. (2014) was the first systematic review on the relationship between MeHg exposure from seafood consumption and risk of developmental neurotoxicity. Their review included 164 studies of women and infants from 43 countries. They found that the fish-consuming populations living along rivers near small-scale 
gold mining and consumers of marine mammals in Arctic regions had MeHg intake several times higher than the FAO/WHO reference. In a comment letter, Myers et al. (2015) highlighted the importance of including the benefits of nutrients in fish into the risk assessment, particularly among the low- and middle- income countries where fish consumption is high and resources are limited.

\section{Environmental Exposure and Risk Assessment}

The World Health Organization (WHO 2010) recognized the importance of collecting sitespecific data of Hg concentrations in fish and seafood around the world as there is a high intraspecies variation that is determined by the local environment. The report also identified the lack

of data for many areas of the world outside of Europe, the US and Japan. This highlight the need for collecting local data for exposure assessment and there is a current effort by the Global Environmental Monitoring System - Food Contamination Monitoring and Assessment Programme (GEMS/Food) of WHO to collect contaminant data from foods, including Hg in fish, data from all countries for the assessment of their contribution to total human exposure, and significance with regard to public health and international trade.

Most of the papers reported measured Hg concentrations in food or other matrices and estimate human exposure using dietary survey information or biomonitoring results. There are ongoing total diet studies or national health and nutritional examination survey which reported food concentrations and/or biomonitoring of contaminants including $\mathrm{Hg}$ in the general populations at the national level, e.g. in France (Arnich et al. 2012) and in Korea (Park et al. 2014). More 
importantly, there is an increasing number of data coming from developing countries, e.g. Nepal (Thapa et al. 2014), Peru (Diringer et al. 2015; Ashe 2012), Ghana (Rajaee et al., 2015), and Suriname (Peplow \& Augustine 2012), etc. Also, more studies were designed to target the specific sub-populations that have a different cultural background or a local fish-heavy diet. For example, the Caribbean immigrant community in Brooklyn, New York (Geer et al. 2012) or the women of childbearing age in Duval County, Florida (Traynor et al. 2013). There were also reports studying potential exposure from known hot spots such as the historically polluted area in

southern Italy (Bonsignore et al. 2013). As aquaculture is expected to gain global prominence in seafood supplies, it is important to monitor Hg levels in farm fish or shellfish, e.g. DelgadoAlvarez et al. (2015) reported Hg in farmed shrimp in NW Mexico and characterized the risk of exposure is low using national consumption rate. Increasing evidence is showing that rice can be an important source of Hg among certain populations in China and other Asian countries (Li et al. 2012; Li et al. 2014; Zhang et al. 2014) but this has yet to be studied in other geographic regions. It has been known that $\mathrm{Hg}$ is widely used in cosmetic products but the scale of human exposure from hand cream use was recently reported (Hamann et al. 2014). This can be a major source of $\mathrm{Hg}$ in many populations and the exposure can be avoided by stricter regulation and education/communication.

\section{Kinetics and biomarkers}

In order to assessment the effects of $\mathrm{Hg}$ on health, it is important to establish a quantitative doseresponse relationship. It is particularly challenging for $\mathrm{Hg}$ as $\mathrm{Hg}$ can exist in different forms including elemental mercury $\left(\mathrm{Hg}^{0}\right)$, divalent mercury $\left(\mathrm{Hg}^{2+}\right)$ and organic mercury (mainly as 
methylmercury, MeHg). Exposure sources, target organs, toxicity, and metabolism differ with each chemical form. For example, most MeHg exposure comes from consuming fish and seafood. MeHg has the highest bioavailability compared to the other forms and easily absorbed by the digestive tract, entering the central nervous system (CNS) after passing the blood-brain barrier (BBB). The result is permanent injury to the CNS, particularly in the developing fetus (UNEP 2008). Elemental Hg exposure mainly results from dental amalgam restorations. Additionally, workers at artisanal and small-scale gold mining (ASGM) sites also experience high exposures to elemental mercury. Target organs here include the brain and kidneys (UNIDO 2008). There are two ways to assess exposure or dose. The first one is to estimate external dose by measuring concentrations in foods or air or water and multiplied by the frequency of exposure like consumption rate or inhalation volume over time. The second one is to estimate $\mathrm{Hg}$ body burden by measuring Hg concentrations in tissues such as hair, urine, blood, nails, cord tissues or blood, and placenta. Both approaches involve challenges and uncertainty. Therefore, most studies reported adjusted R(2) of less than 0.5 when comparing estimated dietary exposure to blood Hg concentration using regression analysis. For example, You et al. (2014) performed multiple regression analysis on dietary estimate and blood concentrations of 1,866 adult participants in Korea and reported the adjusted $\mathrm{R}(2)=0.234$. Further studies with more precise estimation of dietary mercury intake are required to evaluate the risk for $\mathrm{Hg}$ exposure by foods and assure risk communication with heavily exposed groups.

Human absorption of liquid $\mathrm{Hg}^{0}$ is minimal, and acute toxicity does not occur even when the liquid mercury used in thermometers is accidentally ingested (WHO, 1976). The problem arises when liquid mercury vaporizes into the gaseous phase, which causes acute interstitial pneumonia 
when inhaled at a high concentration. Approximately $80 \%$ of inhaled gaseous $\mathrm{Hg}^{0}$ is absorbed into the blood and easily passes through the blood-brain barrier in its un-oxidized form, thereby reaching the brain and damaging the central nervous system (WHO, 1976). With time, gaseous $\mathrm{Hg}^{0}$ in the body is oxidized to $\mathrm{Hg}^{2+}$, which accumulates in the kidneys and causes damage there (UNIDO 2008). The biological half-life of Hg absorbed from vapour into the blood is approximately 2-4 days when $90 \%$ is excreted through urine and feces. Absorption of $\mathrm{Hg}^{2+}$ through the digestive tract is comparatively low. However, a large intake of $\mathrm{Hg}^{2+}$, such as in accidental or suicidal ingestion, causes digestive tract and kidney disorders resulting in death (WHO, 1990). The major source of MeHg is through fish and shellfish consumption and MeHg was thought to be readily absorbed by the digestive tract. Animal studies indicate that the efficiency of gastrointestinal absorption is usually in excess of $90 \%$ of the oral intake (WHO, 1990). Risk assessors often assumed that $100 \%$ of $\mathrm{Hg}$ in fish is $\mathrm{MeHg}$ and its absorption rate is also 100\% (NRC 2000). Recent studies showed that these assumptions are not necessarily true. Matos et al. (2015) found that cooking increased the concentrations of selenium, $\mathrm{Hg}$ and $\mathrm{MeHg}$ in blue shark meat due to water loss, particularly by grilling. While selenium (Se) bioaccessibility (the amount that is free for absorption) was above $83 \%$ in grilled samples, $\mathrm{Hg}$ and MeHg bioaccessibility was lower in grilled samples with values near 50\%. Afonso et al. (2015) reported that cooking meagre by grilling decreased the bioaccessibility for both Se and Hg; Se bioaccessibility was decreased up to $82 \%$ in grilled farm meagre compared to only up to 54\% for bioaccessibility for Hg and up to 64\% bioaccessibility for MeHg. Jadán-Piedra et al. (2016) also reported a lower bioaccessibility for Hg in cooked swordfish (between 14 and 92\%) than selenium. Most of the solubilization took place in the gastric step, with acidic $\mathrm{pH}$ and higher pepsin concentration but the bioaccessibility of $\mathrm{Hg}$ decreased in the presence of bile salts. Wang 
et al. (2013) measured 10 freshwater and 10 marine fish collected from markets in Hong Kong and reported bioaccessibilities of $\mathrm{Hg}$ and $\mathrm{MeHg}$ ranging from 21.4 to 51.7\% (mean 37.4\%) and 19.5 to $59.2 \%$ (mean $43.7 \%$ ), respectively. These results clearly show that the conservative approach of assuming $\mathrm{Hg}$ in fish to be $90-100 \%$ bioavailable can over-estimate intake by $50 \%$. More research is needed to characterize the absorption rate of different species of fish before a consistent correction factor can be adopted for future risk assessment.

MeHg transport into tissues appears to be mediated by the formation of a MeHg-cysteine conjugate, which is transported into cells via a neutral amino acid carrier protein (NRC, 2000; WHO, 1990). The extent of biotransformation of MeHg in the gastrointestinal tract varies resulting in variability in $\mathrm{MeHg}$ absorption rate. MeHg elimination from the human body occurs slowly with a half-life approximately 70 days and is a major determinant of the $\mathrm{Hg}$ body burden resulting from fish consumption (WHO, 1990). Two recent human trials provided some insight on the variability. Yaginuma-sakurai et al. (2012) estimated that the half-life of T-Hg was calculated from raw data to be $94 \pm 23$ days for blood and $102 \pm 31$ days for hair, but the half-life recalculated after subtracting the background levels from the raw data was found to be $57 \pm 18$ based on blood concentrations measured in 27 healthy adults through fish consumption for 14 weeks, followed by a 15-week washout period after the cessation of exposure in Japan. However, the half-life was estimated to be $64 \pm 22$ days when hair concentrations were used. Rand et al. (2015) measured MeHg elimination rates in eight individuals following the consumption of 3 fish meals in two 75-day trials separated by a 4-month washout period in the United States and estimated that the half-life ranged from 42.5 to 128.3 days. They also found that the ratio of MeHg and inorganic g (I-Hg) in feces varied widely among individuals 
suggesting that faster MeHg elimination is associated with a higher \%I-Hg in feces indicating a more complete de-methylation. Carneiro et al. (2014) also found inorganic mercury in plasma originated endogenously through a demethylation reaction in a population exposed to MeHg. Moreover, age displayed a direct linkage with inorganic Hg levels in plasma. Using a onecompartment model, Jo et al. (2015) estimated that the mean MeHg half-life was $81.6 \pm 8.4$ days for men and $78.9 \pm 8.6$ days for women. Moreover, a recent systemic review concluded modelling studies estimated the half-life of inorganic $\mathrm{Hg}$ in the brain to be very long at 27.4 years, which are consistent with autopsy findings (Rooney, 2014). A number of factors including ethnicity, genetics and diet may influence the variability MeHg disposition and its half-life and more studies are needed. In addition, naturally occurring mercury stable isotope ratios have emerged recently as a powerful tool to further distinguish among different forms of $\mathrm{Hg}$ and better understand its toxicokinetics (Sherman et al., 2013; Sherman et al., 2015).

The preferred biomarker reflects the MeHg concentration in the brain since the brain is the major target organ. Generally, the amount retained in the body becomes stable under constant MeHg exposure and depends on dietary intake. Animal experiments indicate that the ratio of the $\mathrm{Hg}$ concentration in the blood to that in the brain becomes fixed under steady state conditions. Therefore, the Hg concentration in the blood/red blood cells is a good biomarker (WHO, 1990). The Hg concentration in the hair also reflects blood MeHg concentration during hair formation and is frequently used as a biomarker for evaluating MeHg exposure (WHO, 1990). Generally, the Hg concentration in the hair is 250 to 300 -fold higher than that in the blood, because sulfurcontaining proteins rich in the hair bind to MeHg. To compare results of different studies using either blood or hair as biomarkers, the World Health Organization (WHO) recommends Hg hair- 
to-blood ratio of 250 for the conversion of $\mathrm{Hg}$ hair levels to those in whole blood. This encouraged the selection of hair as the preferred analyte because it minimizes collection, storage, and transportation issues. In spite of these advantages, there is concern about inherent uncertainties in the use of this ratio. Liberda et al. (2014) measured total hair and total blood $\mathrm{Hg}$ concentrations in 1,333 individuals from 9 First Nations communities in northern Quebec, Canada and found that their hair-to-blood ratios spanning 3 to 2845. Yaginuma-sakurai et al. (2012) also reported the mean hair-to-blood ratio to be $344 \pm 54$ (S.D.) for the 27 participants of the fish consumption study. Therefore, using the constant ratio hair-to-blood ratio of 250 recommended by WHO to convert hair Hg concentrations to blood concentrations could be unreliable, particularly at the individual level. Therefore, future Hg exposure assessment should refer to blood measurements when there are human health concerns. Also, the use of singular hair concentrations and a standard hair-to-blood concentration conversion should be avoided for individual health risk assessment.

The organ targeted by MeHg exposure during gestation is the fetal brain. For this reason, biomarkers reflecting the MeHg exposure level in the fetus during the gestation are very important for predicting the effects of MeHg on child development. In addition, the MeHg concentration in the fetal blood reaches approximately 2-fold higher than that of the mother, because of active MeHg transport across the placenta (NRC, 2000; WHO, 1990). Therefore, umbilical cord blood is the most desirable biomarker for estimating pre-natal exposure. Concentrations of $\mathrm{Hg}$ in cord blood were reported for various population in China, the United States and Spain (Wu et al. 2013; King et al. 2013; Garcia-Esquinas et al. 2013). Hg concentrations in umbilical cord tissue and placenta have been shown to be useful biomarkers to determine fetal MeHg exposure levels (Sakamoto et al. 2012; Garcia-Esquinas et al. 2013; Jin et 
al. 2013; Chen et al. 2014). Maternal Hg levels in fingernails and toenails at parturition also showed strong correlations with those in cord blood and can be used as biomarkers (Sakamoto et al. 2015).

In summary, it is still a challenge to compare Hg exposure between populations as different biomarkers or methods to estimate exposure were used. More concerted effort to harmonize human biomonitoring survey design and data interpretation is needed. For example, Smolders et al. (2015) reported the first ever such effort to harmonize biomarker data in 17 European countries.

\section{Effects on children development}

Mercury enters the fetus' body through the placenta (NRC 2000). Therefore, the fetus is very susceptible to Hg exposure during organogenesis, a fact that has drawn great attention toward women's health issues worldwide. In the last three decades, many studies have reported negative health outcome corresponds with low-level Hg exposure or environment dose through dietary consumption of seafood (Karagas et al. 2012). In the European Union, it was estimated that more than 1.8 million children were born every year with MeHg exposures above the limit of $0.58 \mu \mathrm{g} / \mathrm{g}$, and about 200,000 births exceed a higher limit of $2.5 \mu \mathrm{g} / \mathrm{g}$ proposed by the World Health Organization (WHO) (Bellanger et al. 2013).

Previous studies have reported that prenatal exposure is associated with low birth weight, delayed neurodevelopment, and growth and development of children (Grandjean et al. 2010). Suboptimal fetal growth has been adversely associated with neurodevelopment in childhood and 
it has even shown an increased risk of chronic diseases in adulthood, such as metabolic syndrome (Fox et al. 2012). Thus, elucidating the associations of environmental contaminants with health and development outcomes is of the utmost importance. As noted by a World Health Organization expert committee (World Health Organization, 2006), addressing such gaps in knowledge requires the design and implementation of prospective longitudinal cohort studies of pregnant women, infants, and children with assessment of their exposure at critical windows of development, along with sensitive health endpoints across the full continuum of development. Several such studies have been conducted to date to assess the effects of prenatal exposure to mercury, PCBs, and lead since these widespread environmental contaminants are known for their adverse effects on neurodevelopment (Grandjean and Landrigan, 2006).

Cohort studies in the Faroe Islands conducted since the 1980s have demonstrated that children exposed to methylmercury in utero exhibit decreased motor function, attention span, verbal abilities, memory, and other mental functions (Grandjean et al., 1997). Overall, the Faroe study found that a doubling of the prenatal mercury exposure for a child resulted in a developmental delay of one to two months at the age of seven years; that is, at the age when the child is expected to enter school. This delay corresponds to about 1.5 IQ points (Grandjean and Herz, 2011) and the neurocognitive impacts persist into adulthood as a small effect on educational achievements was observed at age 22 years (Debes et al., 2013). No effects were found on school performance at age 16 years, and only small effect on educational achievements was observed at age 22 years (Debes et al., 2013). In the Faroese birth cohort study, additional statistical analyses have shown that post-natal MeHg as shown by the child's current blood Hg concentration at age 7 contributed to neurobehavioral delays observed that were mainly 
determined by pre-natal exposure, particularly in regard to visuospatial processing and memory (Grandjean et al. 2012). Similar to the Faroese study, a cohort study conducted on 94 Inuit mother-infant pairs in Arctic Canada who were exposed to elevated of Hg from their marinemammal based diet found that prenatal exposure to MeHg was associated with poorer performance on A-not-B test, which depends on working memory and is believed to be a precursor of executive function, among infants at 6.5 and 11 months (Boucher et al. 2014).

Julvez et al. (2013) studied a subsample $(n=1,311)$ of the Avon Longitudinal Study of Parents and Children conducted in Bristol, UK, and found that the prenatal exposure to Hg was low but was positively associated with IQ, which attenuated after adjustment for nutritional and sociodemographic cofactors. They conclude that in this population with a low level of MeHg exposure, there were only equivocal associations between MeHg exposure and adverse neuropsychological outcomes. They suggested that heterogeneities in several relevant genes in the studied population might confound their results. Genetic polymorphism as a disposition for Hg toxicity was reported in a cohort study started in 2006 in Korea (Lee BE et al. 2010) in which maternal and cord blood Hg levels were associated with lower birth weight for mothers with both GSTM1 and GSTT1 null genotype. The importance of genetic factor of Hg toxicity research will be discussed in details in a later section.

As Japan and Korea are two major fish consuming countries in the world, results from the cohort studies conducted in these two countries attracted worldwide interests. The cohort study in Japan investigated the effects of prenatal exposure to PCB, Hg and lead on child behavior in 306 30-month-old children from pregnancy and found that internalizing behavior in the children was 
significantly correlated with PCB ( $r=0.113$ ), but showed no significant correlation with either $\mathrm{Hg}$ or lead (Tatsuta et al. 2012). A similar association between intelligence and achievement and PCB was observed among the children at 42-month-old but not with Hg or lead (Tatsuta et al. 2014). In contrast, Kim BM et al. (2011) studied 921 mother-child pair samples in Korea and found that the cord blood mercury level was negatively associated with the infants' attained weight over the first 24 months of age $(\beta=-0.36$. $p=0.01)$. A more detailed comparison of these two cohort studies may be useful in future risk assessment for other fish consuming nations.

Prenatal and early-life exposures to mercury have been hypothesized to be associated with increased risk of autism spectrum disorders (ASDs) (Grandjean \& Landrigan 2014). A crosssectional study examined the potential correlation between hair Hg concentrations and ASD severity among participants $(\mathrm{n}=18)$ using the Childhood Autism Rating Scale (CARS) in a prospective cohort of participants diagnosed with moderate to severe ASD (Geier et al. 2012). Increasing hair Hg concentrations were found to be significantly correlated with increased ASD severity. This study provides biological plausibility for the role of Hg exposure in the pathogenesis of ASDs. Sagiv et al. (2012) conducted a population-based prospective birth cohort recruited in New Bedford, Massachusetts (1993-1998). In multivariable regression models, Hg exposure was associated with inattention and impulsivity/hyperactivity. On the other hand, there was a protective association for fish consumption (>2 servings per week) with ADHD-related behaviors, particularly impulsive/hyperactive behaviors. Their results show that even at lowlevel, prenatal mercury exposure was associated with a greater risk of ADHD-related behaviors, but fish consumption during pregnancy or maternal fatty acid status is protective of these behaviors (Steenweg-de Graaff et al. 2015). These findings underscore the difficulties of 
balancing the benefits of fish intake with the detriments of low-level mercury exposure in developing dietary recommendations in pregnancy. The importance of nutrient interactions on Hg toxicity will be discussed in a later section.

A number of other studies show that exposure to methylmercury does not play an important role in the development of ASD phenotypic behavior. For example, Yau et al. (2014) reported no significant association between ASDs and levels of total Hg measured in maternal serum from mid-pregnancy and infant blood shortly after birth in a study on children with ASD ( $\mathrm{n}=84$ ), children with intellectual disability or developmental delay (DD) $(n=49)$, and general population controls (GP) (n=159). van Wijngaarden et al. (2013) evaluated the association between prenatal methylmercury exposure and ASD phenotype in children and adolescents in the Republic of Seychelles, where fish consumption is high. The Social Communication Questionnaire was administered to parents of a cohort of 1,784 children, adolescents, and young adults. No consistent association between prenatal methylmercury exposure and ASD screening instrument was found. Taken together, this evidence suggests that the role of Hg may be minor and inconsistent and can be masked by the nutritional benefits from fish consumption.

In the next few years, there will be an explosion of data generated by over 10 cohort studies being conducted around the world; e.g. Canada (Thomas et al. 2015), Italy (Deroma et al. 2013), Norway (Veyhe et al. 2015), Spain (Llop et al. 2012), Poland (Polanska et al. 2013), Amazonia, Brazil (Marques et al. 2013), France (Chan-Hon-Tong et al. 2013), Massachusetts, USA (Kalish et al. 2014), Mexico (Basu et al., 2014), and the Seychelles (Strain et al., 2015). We would expect to obtain more conclusive data on the dose-response relationship between pre-natal 
exposure and a better understanding of the confounding factors including the nutritional and genetic factors. However, as discussed in the biomonitoring section, the use of maternal hair or blood as biomarkers for fetal exposure can generate uncertainty when the dose of different studies was compared. Moreover, the use of different evaluation tools at different age of the infants or children also make the inter-study comparison of effects challenging. More harmonization efforts are needed to integrate the future database for risk assessment purposes. 


\section{Effects on fish consuming adults}

Current challenges regarding the effects of fish consumption on adults depend on methods/strategies to identify susceptible individuals or populations affected by fishmethylmercury (MeHg) exposure. There are no cases where markers of environmental MeHg exposure from fish consumption are indicators or prodromes of clinical conditions. Because of the complex interaction between fish-related constituents, both covariates, health-promoting and toxic substances, are not always taken into account; furthermore, confounding (constitutional) factors and/or accompanying effect modification in statistical models have frequently produced apparently contradictory or confusing results (Choi et al, 2008). The effects of toxic substances on adults are difficult to disentangle from the functional characteristics of fish consumption. Since the Minamata environmental disaster, human studies have focused mainly on MeHg contamination of fish. The extraordinary circumstances in post-war Japan and the highly polluted Minamata Bay contaminated fish to a level not found elsewhere, with Hg concentration reaching in excess of $20 \mu \mathrm{g} / \mathrm{g}$ fish (Clarkson, 1998). These special circumstances turned ordinary fish consumption into a tragic and emblematic environmental disaster. Hair-Hg concentrations of fish consumers during the `Minamata disease` outbreak ranged from $191 \mu \mathrm{g} / \mathrm{g}$ to $705 \mu \mathrm{g} / \mathrm{g}$ (Koos and Longo, 1976; Harada, 1982). A recent study in Japan showed that residents who were exposed to elevated MeHg historically still showed significant functional deficit decades later (Ushijima et al. 2012).

However, Amazonians who consumed large amounts of fish showed Hg concentrations as high as 90.6 to $303.1 \mu \mathrm{g} / \mathrm{g}$ without displaying the clinical symptoms of 'Minamata disease' (Boischio and Barbosa, 1993). Moreover, a cross-sectional study also reported no observable effects on 
neurological outcomes among whale meat consumers in Japan who had high mercury exposure (average hair Hg concentration of $14.9 \mathrm{ug} / \mathrm{g}$ ) (Nakamura et al. 2014). The authors suggest that the high selenium intake offered a protective effect against the Hg toxicity. Fillion et al. (2013) reported color vision loss increased with hair Hg and decreased with plasma Se and \% of omegafatty acids among residents in the Brazilian Amazon. More details on nutrient interactions will be discussed in a later section.

It has been over 10 years since the association of tissue Hg concentrations and cardiovascular outcomes were suggested (Guallar et al, 2002) but inconsistent outcomes are still reported. A study of Amazon tribes suggested that fish consumption (hair-Hg) is inversely associated with age-related increases in blood pressure (Dórea et al., 2005); however, an opposite conclusion was reached by Fillion et al. (2006) with non-Amerindian populations. Choi et al. (2015) also showed that blood serum ferritin and mercury concentrations were associated with the prevalence of hypertension and that simultaneously elevated serum ferritin and mercury concentrations are related to the risk for hypertension in men Korea. However, in a cross-sectional study of the U.S. general population, Park et al. (2013) found no association of hypertension with blood mercury but a suggestive inverse association with urinary mercury. Nevertheless, some authors suggested a dose-response between Hg exposure and cardiovascular health (Roman et al. 2011). It seems that the cause-effect relationship is far from conclusive and future prospective studies are warranted. 
There is emerging evidence on the positive relationship between Hg exposure and metabolic syndrome. In a cross-sectional study, the blood Hg concentrations of 2,114 healthy adults in Korea (geometric mean of $3.90 \mu \mathrm{g} / \mathrm{L}$ ) showed a positive association with body mass index, waist circumference, diastolic blood pressure, total cholesterol, and triglyceride after adjustment for covariates (Eom et al. 2014). Also, Hg exposure was significantly associated with metabolic syndrome and their components such as obesity and increased fasting glucose. These results show that Hg exposure is influenced by sociodemographic factors and individual lifestyles including dietary habits and is associated with metabolic syndrome. Moreover, He et al. (2013) conducted a prospective cohort of 3,875 American young adults, and found that toenail mercury levels are associated with incidence of diabetes over 18 years of follow-up after adjusting for age, sex, ethnicity, study center, education, smoking status, alcohol consumption, physical activity, family history of diabetes, intakes of long-chain n-3 fatty acids and magnesium. The hazard ratio (95\% CI) of incident diabetes compared the highest to the lowest quintiles of mercury exposure was $1.65(1.07-2.56$; $\mathrm{P}$ for trend $=0.02)$. This is the first time an epidemiological studying showing that people with high mercury exposure in young adulthood may have elevated the risk of diabetes later in life. Future studies should collect more information on the potential effects of $\mathrm{Hg}$ on metabolic syndrome.

\section{Health hazards of artisanal and small-scale gold mining}

Liquid mercury $\left(\mathrm{Hg}^{0}\right)$ is applied in artisanal and small-scale gold mining (ASGM) to extract gold from ore. Gold containing ores are grinded, mixed with liquid mercury and panned. During this process gold binds to mercury forming an amalgam. The amalgam is then smelted; mercury being vaporized and gold remains. The panning and smelting expose the smelters and the 
inhabitants of the mining village to toxic mercury vapor $\left(\mathrm{Hg}^{0}\right)$ (Cordy et al., 2013; Cordy et al., 2011; De Miguel et al., 2014; Gonzalez-Carrasco et al., 2011). Once mercury is released it methylates in the aquatic food chain, and becomes bioavailable. Especially mercury-polluted waters, coming from ASGM areas, can contaminate fish leading to high methylmercury levels (MeHg) (Barbieri et al., 2009; Castilhos et al., 2006; De Miguel et al., 2014; Diringer et al., 2015; Dórea, 2008; Frery et al., 2001; Niane et al., 2015). Mercury can accumulate in rice grown in ASGM areas and ingestion of this polluted rice contributes to methyl-mercury exposure of the population (Bose-O’Reilly et al., 2016; Feng et al., 2008; Krisnayanti et al., 2012; Li et al., 2015; Li et al., 2014; Rothenberg et al., 2014). Miners and community members in ASGM areas are constantly exposed to elemental mercury vapor, and depending on the local situation to ingestion of MeHg from local fish and/or rice. Exposure scenarios are similar downwind and downstream from mining areas.

The exposure to mercury in ASGM areas shows high levels of mercury in human specimens as several studies showed (Gibb and O'Leary, 2014; Kristensen et al., 2013). Both reviews showed, that miners and their families are exposed to mercury vapor; that the exposure with inorganic mercury vapor is high, that fish contains MeHg; and that toxic effects have to be considered. Mercury levels in any analyzed biomarker were higher compared to control groups or reference values. Smelting and panning did lead to high and very high levels of mercury, especially in urine, but also in blood and hair. Smelters showed in up-to 80\% typical signs of chronic mercury intoxication, mainly neurological symptoms like ataxia, tremor and coordination problems (Bose-O'Reilly et al., 2010a; Bose-O'Reilly et al., 2010b; Drasch et al., 2001; Lettmeier et al., 2010; Steckling et al., 2011; Steckling et al., 2014). 
World Health Organization (WHO) is concerned about mercury as a health risk for miners and population in ASGM areas: "Mercury exposure in ASGM communities is associated with adverse health effects including kidney dysfunction, autoimmune dysfunction, and neurological symptoms" (World Health Organization, 2013).

ASGM affects approximately 15 million miners globally, as well as other community members, and the population downwind and downstream of mining areas, causing a serious public health problem (Spiegel et al., 2005; Wade, 2013). A burden of disease study for Zimbabwe showed that chronic mercury intoxication ranks within the top 20 health hazards of the country (Steckling et al., 2014; Steckling et al., 2015). Mercury is a serious health problem especially for children (Afandiyev et al., 2011; Bose-O`Reilly et al., 2010c). The health hazards for children in ASGM areas are less known, only a few publications exist (Bose-O'Reilly et al., 2008a; Grandjean et al., 1999). Children are exposed by living in ASGM areas, inhaling mercury fumes and ingesting mercury from fish and/or rice. Even worse off are children working in ASGM areas, performing all different kind of child labor, including handling, inhaling and ingesting toxic mercury (Amon et al., 2012; Kippenberg, 2011). The exposure to mercury leads to increased mercury levels in urine, blood and hair (Bartrem et al., 2014; Hruba et al., 2012; Ohlander et al., 2013). Clinical symptoms of chronic mercury intoxication can be observed (Bose-O'Reilly et al., 2008a). Increased levels of mercury can be found in breast-milk, contributing to an additional exposure pathway for breast-fed infants (Bose-O'Reilly et al., 2008b). There are concerns, that mercury in breast-milk does have a negative effect on the breast-fed child (Al-Saleh et al., 2013; Dórea, 2004; Dórea, 2014). There is a complete lack of studies to investigate the possibility that 
mercury exposure during pregnancy in ASGM areas might have a negative effect on the pregnancy outcome.

Mining activities do have a negative effect on the health of miners and the community members. Mercury is a serious environmental pollutant and health hazard in ASGM areas. Data for human biomonitoring results show increased levels of mercury in certain mining areas (Baeuml et al., 2011; Kristensen et al., 2013). Data for health effects are rare (Gibb and O'Leary, 2014). Other possible health hazards due to mining are accidents in tunnels, shafts, and open pits, available data is rare (Calys-Tagoe et al., 2015; Hentschel et al., 2002). The use of cyanide is not controlled or monitored, even so possible negative health effects are likely (Donato et al., 2007; Obiri et al., 2006). Other hazards are noise and dust, cadmium, lead and arsenic (Amedofu, 2002; Bartrem et al., 2014; Basu et al., 2015; Basu et al., 2011; Burki, 2012; Chadambuka et al., 2013; Dooyema, 2010; Greig et al., 2014; Lkhasuren et al., 2007; Ono et al., 2012). The baseline data for these hazards is insufficient to estimate the real risk for the health of miners and community members in ASGM areas. To obtain more data integrated assessments are necessary (Basu et al., 2015). To analyze mercury laboratories with appropriate equipment and trained staff are needed. Health care providers, including doctors, nurses, pharmacists and community health workers, need the training to be able to diagnose and treat chronic mercury intoxication (Bose-O'Reilly et al., 2008c). Intoxicated people need proper treatment with detoxifying medication (chelating agents). The available drugs need to be licensed and made available by the respective national authorities. Appropriate health care centers in ASGM areas have to be set up and funded. Health data from ASGM areas requests to be collected, analyzed and consequences of the results need to be taken by stakeholders and policymakers. Screening programs for pregnant women, children 
and miners are needed to identify intoxicated people. Regular human-biomonitoring should be established to be able to identify hot spots, and to evaluate intervention programs. To reduce knowledge gaps studies are needed - accidents, noise, dust, cyanide, cadmium, arsenic and lead need to be urgently assessed. Studies to assess the specific risk for children and infants are needed, like birth cohorts to improve the knowledge of per- and postnatal effects of mercury. The awareness, that mercury is a serious health hazard, is the key to required urgent actions and needs to be increased on all levels, from national policymakers, regional stakeholders, to health experts and the population in mining areas.

\section{Effects of Dental Amalgam}

There remains significant concern worldwide about the potential health effects of exposure to mercury vapour (Hg0) that may be released from dental amalgam restorations. This form of restoration has been used for over 100 years, and most standard formulations contain approximately 50\% elemental Hg. Expert panels from across Europe, United States, Canada, and Australia among others have concluded that there is no strong scientific evidence to make a causal link between dental amalgam restorations and adverse health outcomes except for some rare cases of hypersensitivity in some people (Brownawell et al., 2005). Nonetheless research continues in this area. Foremost is that Hg exposures have been steadily declining among dental professionals in many regions. For example, through a biomonitoring program run by the American Dental Association on their membership, researchers have shown a decrease of nearly 10-fold in the urinary Hg values between 1975 and 2012 (Goodrich et al., 2015). In addition to 
continued biomonitoring efforts, in recent years, a number of new paradigms in the Hg mercury sciences have been applied to studies of dental professionals that are briefly reviewed here.

Stable isotopes of Hg have emerged as an analytical tool to better track $\mathrm{Hg}$ in the ecosystem and people as well as distinguish between exposure to MeHg and Hg0. Characterization of massindependent fractionation of $\mathrm{Hg}$ stable isotopes in human biomarkers (blood, hair, urine) can be used to differentiate between exposure to MeHg derived from seafood (with high positive massindependent fractionation; i.e., $\Delta 199 \mathrm{Hg}$ values) and geologically derived $\mathrm{Hg}$ such as $\mathrm{Hg} 0$ inhaled from dental amalgams (exhibits no mass-independent fractionation). In contrast to massindependent fractionation, mass-dependent fractionation of the isotopes can be used to understand processes occurring in the body such as MeHg demethylation. Sherman et al. (2013) characterized Hg stable isotopes in hair and urine samples from a small group of 11 dental professionals and drew two main conclusions. First, the stable isotope results confirmed that $\mathrm{Hg}$ measured in hair largely originates from seafood ingestion, which is an observation made by many others. Second, a large percentage of Hg in urine may be derived from the ingestion and demethylation of MeHg that is derived from seafood. This contradicts a widely held assumption that $\mathrm{Hg}$ in urine is derived from exposure to inorganic sources of $\mathrm{Hg}$. This assumption held true from those individuals who had more than 10 personal amalgams but for participants with less than 10 personal amalgams, $>70 \%$ of the urinary $\mathrm{Hg}$ was estimated to be derived from seafood. This finding raises important questions about how Hg exposure assessments are performed in dental populations but also the general public. Since the publication of this work by Sherman et al. (2013), other stable isotope studies have been performed with human populations that are deepening our understanding of how people handle Hg (Li et al., 2014; Sherman et al., 2015). 
Genetic polymorphisms have emerged to help us better identify biomarkers, sensitive subgroups, and life stages. This is particularly important for research on dental amalgams given the rare cases of hypersensitivity that occur. It begs the question whether genetic susceptibilities to Hg exist thus rendering some individuals hypersensitive. Studies involving dental professionals have documented a role of genetics in terms of modifying the relationship between $\mathrm{Hg}$ exposure and adverse health outcome for the following: 1) a polymorphism in CPOX4 and altered porphyrin excretion (Woods et al., 2005); 2) a polymorphism in BDNF and performance on neurobehavioral tests such as hand steadiness and finger tapping, both of which are critical to dental professionals (Echeverria et al., 2005); 3) a deletion in the SLC6A4 promotor on finger tap and hand steadiness tests (Echeverria et al., 2010); and 4) a polymorphism in BDNF with indicators of anxiety and memory (Heyer et al., 2004).

\section{Effects of $\mathrm{Hg}$ in cosmetics and in Thimerosal-containing vaccines}

Exposure to mercury occurs by inhalation (metallic Hg vapor/ionized mercury), ingestion (methylmercury-MeHg), through the skin in cosmetic products (skin-lightening creams), and injection (ethylmercury-EtHg). Skin-lightening creams are used by pregnant and lactating mothers (Al Saleh, 2016) and Thimerosal-containing vaccines are given to pregnant mothers, newborns, neonates, and children (Marques et al, 2016) in less developed countries. We do not have established criteria for neurologic diagnosis due to low doses of these types of $\mathrm{Hg}$ exposure. Because of the vulnerability of young humans to the intellectual disabilities provoked by $\mathrm{MeHg}$ (Cohen et al, 2005) and EtHg (Geier et al, 2015), concerns are justifiably heightened (Dórea, 2015). When combined exposures to MeHg and EtHg are evaluated, increases in neurodevelopmental delays may occur (Marques et al, 2016). Currently, only less developed 
countries use pediatric Thimerosal-preserved vaccines. In these populations, the exposure to both forms of organic Hg is associated to fish (MeHg in an important food source) and vaccine (an essential item of modern medicine to prevent infectious diseases). Concerns about any one single chemical form of exposure are compounded when we consider the cumulative total Hg load. Therefore, to safeguard neurological development in children, it is important that all forms of Hg, inorganic or organic (not only environmental MeHg but also iatrogenic EtHg) exposure be identified and reduced.

\section{Nutrients reported to modulate $\mathrm{MeHg}$ toxicity}

Research on the developmental effects of MeHg exposure from fish consumption with background contamination has been extensive albeit, there is still substantial scientific uncertainty about the consequences, if any, of low-level MeHg exposure and the safety or risk of fish consumption. It is, however, clear that metabolism and/or toxicity of MeHg are modulated by intake of dietary nutrients including those concomitantly eaten with fish (Gagné et al, 2013). The mechanisms underlying the potential protective effect of foods on mercury exposure and toxicity are not fully understood albeit is an area of growing scientific interest (Donaldson et al., 2010; Deroma et al, 2013, Choi et al, 2014, Strain et al, 2015).

Several nutrients and foods have been associated with modulating MeHg including n-3 polyunsaturated fatty acids (PUFA), selenium, iodine, tomatoes fruit and antioxidants such as lycopene proanthocyanidins and tea polyphenols (Liu et al., 2014; Yang et al., 2012; Gagné et al, 2013). More recently the impact of the GUT microbiome has received attention for its role in the excretion of MeHg (Rothenberg et al, 2016; Rand et al, 2016). With respect to inorganic 
mercury, animal studies have identified antioxidants, including lycopene, as potential protective factors against toxicity induced by MeHg (Deng et al., 2012).

The primary route of MeHg in the human diet is from consumption of fish with the species and age of the fish impacting on the amount of MeHg. Fish is an important source of nutrition worldwide being the primary source of protein for approximately four billion people (FAO 2012). While the recently-ratified Minamata Treaty will reduce future anthropogenic releases of mercury and mercury compounds (Landrigan et al. 2013), about 70\% of atmospheric Hg emanates from natural sources and re-emissions (UNEP 2013). Therefore, exposure to MeHg from fish consumption will continue to pose a potential risk to child development. Contrary to this, the ALSPAC study reported that the contribution of seafood (white fish, oily fish, and shellfish) accounted only for an estimated 6.98\% of the variation in blood mercury levels in the pregnant women included in the analysis (Golding et al, 2013). In this study, herbal teas were unexpected dietary predictors of total blood mercury. It must be noted that self-reported dietary data is challenged by misreporting and care should be taken when using such data to inform health policy (Hebert et al, 2014). Furthermore, that this study does not take into account variability in absorption or the metabolism of $\mathrm{Hg}$. More recently exposure to $\mathrm{MeHg}$ from foods sources other than fish has received much-needed attention. Exposure to MeHg from the consumption of rice contaminated as a result of inorganic mercury pollution has given concern as rice is a stable food for billions especially in East and Southeast Asia (Barrett, 2010; Lin et al, 2012). In some Hg mining regions of China, the MeHg concentrations of rice is much higher than the national limit of $\mathrm{Hg}$ in food (Meng et al., 2014). Similarly, vegetables and meat produced in these regions have been shown to contribute largely to the total mercury exposure. 
Rice lacks the nutrients which are proposed to offset the neurotoxicity of MeHg (Barrett, 2010) therefore research is needed to determine the effects of consuming rice and other foods contaminated with MeHg on health effects especially during pregnancy and child development.

Balancing the benefits of fish intake with the detriments of low-level mercury exposure has provided a challenge to researchers when devising dietary recommendations in pregnancy (Teisl et al. 2011). Fish contain nutrients essential for maternal and fetal health, including long-chain polyunsaturated fatty acids (PUFA), selenium, vitamin E, and other nutrients (Myres et al, 2007). Fish are the primary source of docosahexaminic acid (DHA) which is a major lipid in the brain and essential for normal brain function (Kuratko et al. 2013) therefore limiting fish consumption during pregnancy could adversely affect child development. Guidelines from Australia, Europe, and the USA all encourage pregnant women, those who may become pregnant, breastfeeding mothers and young children to eat more fish and to eat a variety of fish from a choice that is lower in mercury. A recent joint report from the FAO/WHO recommended that the neurodevelopmental benefits of consuming fish be explicated (FAO/WHO, 2010). Nevertheless, it has been proposed that the present fish consumption advisories have led to a decline in fish intake by pregnant women with no clear indication that this trend has benefitted children's health (Bloomingdale, 2010). Uncertainty about possible developmental effects continues to represent a challenge for devising public policies on fish consumption. As previously discussed mercury is a powerful neurotoxin harmful to the developing brains of the fetus and young children. The Environmental Working Group (EWG) in the USA recommend that more advice is needed for pregnancy women on the type of fish they should consume as the current advice may result in exposure to high mercury and low omega-3 fatty acids (Lunder, 2016). The EWG conducted a 
study on pregnant women who were frequent consumers of seafood and observed that some $30 \%$ and $60 \%$ had hair mercury concentrations $>1 \mathrm{ppm}$ and $>0.58$ ppm respectively; values reported to be associated with negative outcomes to the developing fetus (Grandjean et al, 2012).

Furthermore, few of the pregnant women within this study met the dietary intake recommendations for omega-3 fatty acids despite being frequent seafood consumers. Several studies have now shown that the benefits of seafood consumption during pregnancy are apparent when mercury concentrations are low (Oken et al, 2008; Sagiv et al, 2012). The EWG propose that pregnancy women should be provided with more advice by the FDA and EPA on seafood which is a rich source of omega-3 fatty acids and low in mercury. Studies have revealed that the association between maternal fish consumption and child development outcomes is far more complex than initially thought. Results from prospective mother-child cohorts in the United Kingdom, Spain and the Republic of Seychelles have shown no adverse associations between prenatal MeHg exposure and children's subsequent development (Davidson et al, 1998; Myres et al, 2003; Daniels et al, 2004; Davidson et al, 2008; Strain et al, 2008; Strain et al 2015; Llop et al, 2012) whilst studies from New Zealand, the Faroe Islands, and the United States have reported adverse developmental influences of prenatal MeHg exposure (Crump et al, 1998; Grandjean et al, 1997; Sagiv et al, 2012; Debes et al, 2016). Variability in study designs, populations, genetic susceptibility and nutrition may explain some of the inconsistencies between studies. Research on fish consumption during pregnancy indicates that allowing for PUFA present in fish in statistical analysis may influence whether or not neurocognitive associations with MeHg are found (Budtz-Jørgensen et al., 2007; Strain et al 2012; Strain et al, 2015). The n3 PUFA in fish has been increasingly identified as having health benefits (Karimi et al, 2014). 
The toxic effects of MeHg on the developing brain is considered to be mediated by oxidative damage, which in turn causes inflammation (do Nascimento et al, 2008). Maternal PUFA status, a putative indirect marker of inflammation, is suggested to modify MeHg associations with psychomotor development (Strain et al, 2012). The relative amounts of n-3 PUFA available in the diet are important for determining the physiologic n6/n3 balance and the maternal inflammatory milieu. Incorporation of the less pro-inflammatory n-3 PUFA, may reduce any possible inflammatory insults following MeHg exposure in the brain and subsequently benefit child development ( Janssen et al, 2013; Strain et al, 2015).

It is well known that fish are also rich in a number of micronutrients such as selenium and iodine which are nutrients known to enhance neurodevelopment. Selenium (Se) is an essential nutrient that is required for normal function of enzymes that protect brain and endocrine tissues from oxidative damage (Rayman, 2012). Selenium has received attention as a potential protector from methylmercury toxicity in populations with high fish consumption (Berr et al, 2009; Ralston \& Raymond, 2010; Carocci et al, 2014; Bjørklund, 2015). It is proposed that the toxicity of MeHg is related to the amount of selenium where the formation of MeHg-selenocisteine compounds is proposed to reduce the bioavailability of selenium and thus interferes with the synthesis of the selenium-dependent antioxidant enzymes that provide antioxidant protection to the brain (Raymond \& Ralson, 2009). Nevertheless the role of Se in MeHg intoxication remains to be confirmed due to inconsistencies in animal studies along with a lack of evidence from epidemiological studies (Farina et al, 2011). Fish is also the major dietary source of iodine which is a component of the thyroid hormones, thyroxine (T4) and tri-iodothyronine (T3) and essential for neurodevelopment (Pearce, 2013). Mercury has been found to be inversely associated with 
thyroid hormone concentrations in adults and immunotoxic mechanisms have been suggested (Chen et al, 2012). Dietary iodine is taken up by the thyroid for synthesis of these hormones, stimulated by thyroid stimulating hormone (TSH) in a pathway which also requires selenoprotein iodothyronine deiodinase (DIO) enzymes (Skeaff, 2011). It is proposed that $\mathrm{Hg}$ accumulates in the thyroid, reduces iodide uptake at the sodium/iodide symporter and inhibits DIO activity (Chen et al, 2011). Furthermore, insufficient selenium can impair thyroid hormone production and reduce antioxidant status, which can exacerbate iodine deficiency. Consequently, there is believed to be interdependence between selenium and iodine in their effects on thyroid function and neurodevelopment and these nutrients may modify the effects of MeHg albeit much research is needed to fully elucidate these relationships.

Research carried out in the Brazilian Amazon identified fruit consumption as having a protective effect against MeHg exposure (Passos et al., 2007) and propose that the soluble dietary fibre and prebiotic nutrients found in fruit could be impacting on MeHg metabolism in the GUT. The gut flora plays a predominant role in the excretion of methylmercury through demethylation and the release of inorganic mercury (Clarkson and Magos, 2006). A study of Inuit preschool children reported an inverse relationship between the consumption of tomato products and blood mercury concentrations (Gagné et al, 2013). Along with having putative effects on the GUT microflora impacting on demethylation rates, they also suggest that a good supply of dietary antioxidants, including lycopene in tomatoes, would preserve glutathione enabling it to bind MeHg and contribute to its secretion into bile as glutathione-mercury complexes (Clarkson and Magos, 2006). Silva de Paula et al. (2016) found protective effects of niacin (rich in fish) against MeHginduced genotoxicity and alterations in antioxidant status in rats. It is clear that some nutrients 
consumed concomitantly with MeHg in the diet may ameliorate its toxicity albeit much more research is needed to fully investigate the mechanisms of action.

\section{Genetic factors}

Over the past decade, scientific studies have emerged to document that genetic and epigenetic factors may influence mercury exposure and associated health risks (reviewed by Basu et al., 2014; Llop et al., 2015). The results of these studies are helping to increase our understanding of Hg's mechanisms of actions, and in turn, this knowledge is expected to help us better identify biomarkers, sensitive sub-groups, and life stages. Further, the outcome of these studies may help reduce uncertainty in our risk assessments and thus improve decision-making.

As background, several biological pathways (e.g., DNA repair, chemical biotransformation) have evolved to help protect the human body from environmental insults. The genes in these pathways are often referred to as environmentally responsive genes, and these genes may have variant forms to help living organisms cope with a changing environment. Environmentally responsive genes important to how the human body handles Hg can include those involving glutathione (e.g., glutathione s-transferases), proteins that bind and transport Hg (e.g., metallothioneins), and xenobiotic transporters (e.g., solute carriers). Polymorphisms in these environmentally responsive genes are ubiquitous across populations, and thus may influence the absorption, distribution, metabolism, and elimination of $\mathrm{Hg}$.

Cross-sectional, hypothesis-driven studies from across the world are beginning to show that 
genetic polymorphisms in selected environmentally responsive genes can be associated with the main effect (i.e., carriers of wildtype and variant forms have different Hg biomarker levels) and gene-environment interactions (i.e., exposure-biomarker relationships are different between carriers of the wildtype and variant form). Such observations have been made on studies involving, for example, dentists (Goodrich et al., 2011; Yang et al., 2012; Parajuli et al., 2016), students (Gundacker et al., 2007; Gundacker et al., 2009), riverine populations (Barcelos et al., 2013; Barcelos et al., 2015) and gold miners (Custodio et al., 2005; Harari et al., 2012; Engstrom et al., 2013). The work to date has largely focused on adults and much less is known about early-life exposure situations. Further, most of the studies have focused on populations exposed mainly to inorganic sources of $\mathrm{Hg}$, and the $\mathrm{MeHg}$ exposures are generally within background levels.

Moving beyond the influence of genetic polymorphisms on $\mathrm{Hg}$ exposure biomarkers (i.e., toxicokinetics), there are a handful of studies showing that genes are important in the toxicodynamics of Hg. A study from Korea documented that the Hg-associated risk of low birth weight in newborns was greater in carriers with deletion polymorphisms of GSTM1 and GSTT1 (Lee et al., 2010). A series of studies involving dental professionals documented the importance of considering genetic polymorphism information when address exposure-outcome relationships (Woods et al., 2005; Echeverria et al., 2006; Echeverria et al., 2010), and these are elaborated upon later in this paper. There are relatively few health studies that have considered genetics and much more work is needed in this area particularly in terms of expanding the number of polymorphisms studied and how they are selected, and involving cohort studies with large sample sizes. 
Early life mercury exposure was found to increase the ethnic risk of developing Kawasaki disease (KD), a condition that causes inflammation in the walls of medium-sized arteries throughout the body, including the coronary arteries, which supply blood to the heart muscle. East Asian children are 20 times at risk to develop KD (Mutter \& Yeter 2008). A study conducted in the US showed that African, Asian, Caucasian, and Hispanic children in the US having increasing low-dose exposure to $\mathrm{Hg}$ may induce $\mathrm{KD}$ or contribute to its later development in susceptible children (Yeter et al. 2016). More research is needed to study this disease caused by gene-environmental interactions.

Epigenetics refers to heritable factors that affect gene expression but occur outside of direct changes to the DNA sequence (Head et al., 2012). Such epigenetic factors can be influenced by stimuli such as contaminants but also by psychosocial stress and nutritional status. Epigenetic marks (e.g., DNA methylation, histone modification) left by such stimuli can persist in the absence of the initial stressor, and this supports the notion that exposures to stressors in early life can lead to adverse health outcomes later in life. Epigenetic mechanisms are likely very relevant for Hg (reviewed by Basu et al. 2014 ) as the contaminant is an established developmental toxicant that can have a long latency period between exposure and disease. There is some emerging evidence from both animals (Pilsner et al., 2010; Basu et al., 2013) and humans (Hanna et al., 2012; Goodrich et al., 2013) to suggest that Hg is epigenetically active, and these studies provide a foundation to explore the matter deeper.

The risk assessment of $\mathrm{Hg}$ is challenged because of great inter-individual variability that can 
exist in its exposure and health effect, and the latencies exposure and health effect can range from weeks to years (Canuel et al., 2006; Basu et al., 2014). Variation has largely been addressed by trying to account for biological or environmental factors such as age, sex, accuracy of dietary surveys, and the measurement of other toxicants and nutrients yet the inclusion of such factors has been met with limited success. There is growing evidence that consideration of genetic polymorphisms and epigenetic processes may help better resolve underlying

mechanisms, identify susceptible sub-populations, and ultimately improve risk assessments and decision making. Genes recommended for future studies are outlined in recent reviews by Basu et al. (2014) and Llop et al. (2015).

\section{Risk communication and Policy}

It is expected the global inventory of Hg will decrease and will subsequently lead to a reduction in Hg exposure and health risk when the Minamata Convention is ratified and implemented. However, Sunderland \& Selin (2013) stated that most future emissions scenarios project a 
growth or stabilization of anthropogenic mercury releases relative to present-day levels. Analyses that only consider changes in primary anthropogenic emissions are likely to underestimate the severity of future deposition and concentration increases associated with growth in mercury reservoirs in the land and ocean as mercury already in the environment can be re-emitted via processes in the natural cycle, resulting in a longer lag time before pollution reduction can have a demonstrable effect on the food chain. (Bender et al. 2014; Elsie M Sunderland \& Selin 2013). Seawater mercury concentration trajectories in areas such as the North Pacific Ocean that supply large quantities of marine fish to the global seafood market are projected to increase by more than 50\% by 2050 (Sunderland et al. 2009). Therefore, much research is needed to characterize the physical-chemical-biological interactions in the environment, as well as impacts of environmental management before a direct relationship between anthropogenic emission and exposure among human populations, can be established. Chan \& Jacobs (2013) used a dynamic model to simulate such a complex problem in a stream basin in Kentucky, USA. This example illustrates that it is possible to manage the environmental issues at a local scale if sufficient scientific data are available.

In the near term, health professionals need to implement effective risk management and risk communication programs to minimize exposure risks. The importance of including the nutritional benefits in the risk assessment of $\mathrm{Hg}$ exposure from fish consumption is discussed in the earlier section. The FAO and WHO held an Expert Consultation workshop in 2011 (FAO/WHO 2011) to address the dilemma of fish consumption and proposed an integrative approach that balances the benefits of n-3 polyunsaturated fatty acids with the risks of $\mathrm{Hg}$ among women of childbearing age. Similar risk assessment model has been applied at the national level 
in the US and Europe (Rheinberger \& Hammitt 2012; EFSA Scientific Committee 2015) and at regional levels such as the Canadian Arctic (Laird et al. 2013).

However, issuing dietary advisory may not necessarily lower Hg exposure. One of the reasons is because of the complicated message of different consumption rate for different species of fish (Wenstrom 2014). The message may not be easily communicated to the target population. (Ser \& Watanabe 2012) reported that the public awareness of the fish advisory was very low in both USA. Herdt-Losavio et al. (2014) conducted a cross-sectional study with 421 adults and 207 children (171 adult-child pairs) examining the generational differences in fish consumption and knowledge of benefits/warnings of fish consumption among parents and children. They found that in $71 \%$ of parent-child pairs, both the parent and the child knew of benefits of consuming fish; but only 31\% knew of warnings. Parental consumption of high or moderately-high-mercury fish was related to the child's consumption of fish in the same category. Parents and children need additional education to make better choices about fish consumption. Education should target the family and include specifics about benefits and risks.

On the other hand, one must caution that there is a possibility that a strong emphasis on mercury toxicity may drive the general population towards a trend of lower fish consumption. This may lead to an unnecessary loss of nutritional benefits among the portion of populations that were not at risk of over Hg exposure. A delicate balance and clear communication messages need to be developed. The challenge on issuing fish consumption advice was comprehensively discussed by Nesheim \& Nestle (2014) including the importance to consider the sustainability of fishery stocks globally. Successful cases have been demonstrated in Greenland and Faroe Island that 
with effective communication programs/messages, dietary advisory can result in lowering $\mathrm{Hg}$ burden among pregnant without causing unwarranted anxiety and loss of nutrition benefits (Bjerregaard \& Mulvad 2012; Weihe \& Joensen 2012).

\section{Conclusion}

This critical review has made an attempt to highlight the most important findings in the understanding of health issues related to Hg exposure. A number of knowledge gaps have been identified in each of the areas discussed. Researchers and health professionals need to work closely together to conduct strategic research to address these knowledge gaps so that policy makers can formulate intervention policy based on the best science. Extra efforts are needed to harmonize the research design and methodology so that integrated data can be generated to provide more conclusive evidence. Finally, more resources are needed to devote to knowledge synthesis.

The following is a summary of recommendations from the Panel members:

- Using unvalidated instruments for dietary assessment often resulted in high degree of uncertainty in exposure assessment. Improvement on the accuracy of dietary exposure, for example, using stable isotopes, are needed. 
- Potential new sources of exposure such as rice consumption and skin cream use have not been fully assessed. Research results from multiple countries are needed to assess the scope of the problem nationally and internationally.

- Combined effects of co-exposure with other contaminants e.g. MeHg and PCBs, MeHg and $\mathrm{Pb}, \mathrm{MeHg}$ and $\mathrm{As}$, EtHg and $\mathrm{Al}$, from seafood consumption, will be important for future studies.

- Continuing research efforts on effects of low-dose MeHg exposure on children's health is needed. Future studies need to make an effort to harmonize the parameters measured, for example, the biomarkers used for dose and the neuro-performance assessment tools used for effects.

- Effects of Hg on metabolic syndrome and delayed long-term effects among adults need to be characterized.

- Hg exposures in ASGM communities are amongst the highest worldwide though relatively few health studies have been conducted, and of these, few have accounted for the multiple public health hazards that exist in such communities.

- Potential effects of nutrient interactions needed to be considered in all Hg health studies and more research is needed to quantify the protective effects of food or nutrients to establish effective public health guidelines.

- Genetic research is beginning to show that polymorphisms may help explain interindividual differences in exposure and health effects, though only a handful of genes have been investigated thus far and thus more work is needed to expand the number of targets studied.

- Effective communication messages need to be developed to increase awareness and lower exposure among the seafood consumers, and the ASGM communities.

- Researchers and health professionals should assist policy makers at the national level to implement the Minamata Convention to restrict the use of $\mathrm{Hg}$ and establish national policy based on precautionary prevention strategy. 
- National monitoring programs to ensure the safety of food and nutritional and health surveillance to ensure healthy diet and lifestyles among vulnerable groups.

\section{Acknowledgement}

The authors of this paper were members of the Plenary Panel on Human Health in the $12^{\text {th }}$

International Conference on Mercury as a Global Pollutant held in Korea in June 2015. We

would like to thank the members of the Organizing Committee for the invitation to Panel. We

would also like to thank Ms. Kayla Greydanus for her assistance with the literature review.

\section{References}

Afandiyev, I., et al., 2011. Children's Exposure to Mercury Compounds. WHO Document Production Services, , Geneva, Switzerland.

Afonso, C. et al., 2015. Evaluation of the risk/benefit associated to the consumption of raw and cooked farmed meagre based on the bioaccessibility of selenium, eicosapentaenoic acid and docosahexaenoic acid, total mercury, and methylmercury determined by an in vitro digestion mo. Food chemistry, 170, pp.249-56. Available at: http://www.ncbi.nlm.nih.gov/pubmed/25306342 [Accessed January 25, 2016].

Al-Saleh, I., et al., 2013. Mercury (Hg) exposure in breast-fed infants and their mothers and the evidence of oxidative stress. Biol Trace Elem Res. 153, 145-54.

Al-Saleh I. 2016. Potential health consequences of applying mercury-containing skin-lightening creams during pregnancy and lactation periods. Int J Hyg Environ Health. doi:10.1016/j.ijheh.2016.03.002.

Amedofu, G. K., 2002. Hearing-impairment among workers in a surface gold mining company in Ghana. Afr J Health Sci. 9, 91-7.

Amon, J. J., et al., 2012. Child labor and environmental health: government obligations and human rights. Int J Pediatr. Article ID 938306, 8 pages. doi:10.1155/2012/938306.

Arnich, N. et al., 2012. Dietary exposure to trace elements and health risk assessment in the 2nd French Total Diet Study. Food and chemical toxicology : an international journal published for the British Industrial Biological Research Association, 50(7), pp.2432-2449.

Ashe, K., 2012. Elevated mercury concentrations in humans of Madre de Dios, Peru. PloS one, 7(3), p.e33305.

Axelrad, D. A., et al., 2007. Dose-response relationship of prenatal mercury exposure and IQ: an integrative analysis of epidemiologic data. Environ Health Perspect. 115, 609-15.

Baeuml, J., et al., 2011. Human Biomonitoring Data from Mercury Exposed Miners in Six Artisanal Small-Scale Gold Mining Areas in Asia and Africa. Minerals. 1, 122-143.

Barbieri, F. L., et al., 2009. Mercury exposure in a high fish eating Bolivian Amazonian population with intense small-scale gold-mining activities. Int J Environ Health Res. 19, 267-77. 
Barrett JR. Rice is a significant source of methylmercury: research in china assesses exposures. Environ Health Perspect. 2010 Sep;118(9):a398. doi: 10.1289/ehp.118-a398a.

Barcelos GR, Grotto D, de Marco KC, Valentini J, Lengert Av, de Oliveira AÁ, Garcia SC, Braga GÚ, Schläwicke Engström K, Cólus IM, Broberg K, Barbosa F Jr. 2013. Polymorphisms in glutathione-related genes modify mercury concentrations and antioxidant status in subjects environmentally exposed to methylmercury. Sci Total Environ. 463-464:319-25.

Barcelos GR, Souza MF, Oliveira AÁ, Lengert Av, Oliveira MT, Camargo RB, Grotto D, Valentini J, Garcia SC, Braga GÚ, Cólus IM, Adeyemi J, Barbosa F Jr. 2015. Effects of genetic polymorphisms on antioxidant status and concentrations of the metals in the blood of riverside Amazonian communities co-exposed to Hg and Pb. Environ Res. 138:224-32.

Bartrem, C., et al., 2014. Unknown risk: co-exposure to lead and other heavy metals among children living in small-scale mining communities in Zamfara State, Nigeria. Int J Environ Health Res. 24, 304-19.

Basu N, Head JA, Nam D-H, Pilsner JR, Carvan MJ, Chan HM, Goetz FW, Murphy CA, Rouvinen-Watt K, Scheuhammer AM. 2013. Effects of methylmercury on epigenetic markers in three model species: mink, chicken, and yellow perch. Comp Biochem Physiol Pt C Toxicol. 157: 322-327.

Basu, N., et al., 2011. Multiple metals exposure in a small-scale artisanal gold mining community. Environ Res. 111, 463-7.

Basu, N., et al., 2015. Integrated assessment of artisanal and small-scale gold mining in Ghana--part 1: human health review. Int J Environ Res Public Health. 12, 5143-76.

Basu, N., Goodrich, J., Head, J. 2014. Ecogenetics of mercury: From genetic polymorphisms and epigenetics to risk assessment and decision-making. Environmental Toxicology and Chemistry. 33: 1248-1258.

Bellanger, M. et al., 2013. Economic benefits of methylmercury exposure control in Europe: monetary value of neurotoxicity prevention. Environmental health : a global access science source, 12, p.3.

Bellinger, D. C., 2014. Mercury and pregnancy. Birth Defects Res A Clin Mol Teratol. 100, 1-3.

Bender, M., Lymberidi-Settimo, E. \& Groth, E. 3rd, 2014. New mercury treaty exposes health risks. Journal of public health policy, 35(1), pp.1-13.

Berlin, M., et al., Mercury. In: G. F. Nordberg, et al., Eds.), Handbook on theToxicology of Metals. Elsevier, Amsterdam, 2015.

Bernhoft, R.A., 2012. Mercury toxicity and treatment: a review of the literature. Journal of environmental and public health, 2012, p.460508.

Bjerregaard, P. \& Mulvad, G., 2012. The best of two worlds: how the Greenland Board of Nutrition has handled conflicting evidence about diet and health. International journal of circumpolar health, 71, p.18588.

Bloomingdale A, Guthrie LB, Price S, Wright RO, Platek D, Haines J, Oken E. A qualitative study of fish consumption during pregnancy. Am J Clin Nutr. 2010 Nov;92(5):1234-40. doi: 10.3945/ajcn.2010.30070. Epub 2010 Sep 15.

Boischio, A.A., Barbosa, A. 1993. [Exposure to organic mercury in riparian populations on the Upper Madeira river, Rondonia, Brazil, 1991: preliminary results] Cad. Saude Pub. 9, 155160.

Bonsignore, M. et al., 2013. Mercury in fishes from Augusta Bay (southern Italy): risk assessment and health implication. Food and chemical toxicology: an international journal published for the British Industrial Biological Research Association, 56, pp.184-194. 
Bose-O'Reilly, S., et al., 2008a. Mercury as a serious health hazard for children in gold mining areas. Environ Res. 107, 89-97.

Bose-O'Reilly, S., et al., 2008b. Mercury in breast milk - A health hazard for infants in gold mining areas? Int J Hyg Environ Health. 211, 615-23.

Bose-O’Reilly, S., et al., 2008c. Health and environmental training in mercury-contaminated areas. Int. J. Environment and Health. 1, 621-637.

Bose-O'Reilly, S., et al., 2010a. Health assessment of artisanal gold miners in Indonesia. Sci Total Environ. 408, 713-25.

Bose-O'Reilly, S., et al., 2010b. Health assessment of artisanal gold miners in Tanzania. Sci Total Environ. 408, 796-805.

Bose-O`Reilly, S., et al., 2010c. Mercury exposure and children’s health. Current Problems in Pediatric and Adolescent Health Care. 40, 186-215.

Bose-O’Reilly, S., et al., 2016. A preliminary study on health effects in villagers exposed to mercury in a small-scale artisanal gold mining area in Indonesia. Environ Res (under revision).

Boucher, O. et al., 2014. Domain-specific effects of prenatal exposure to PCBs, mercury, and lead on infant cognition: results from the Environmental Contaminants and Child Development Study in Nunavik. Environmental health perspectives, 122(3), pp.310-316.

Brownawell AM, Berent S, Brent RL, Bruckner JV, Doull J, Gershwin EM et al. The potential adverse health effects of dental amalgam. Toxicol Rev 2005;24: 1-10.

Burki, T. K., 2012. Nigeria's lead poisoning crisis could leave a long legacy. Lancet. 379, 792.

Calys-Tagoe, B. N., et al., 2015. Injury Profiles Associated with Artisanal and Small-Scale Gold Mining in Tarkwa, Ghana. Int J Environ Res Public Health. 12, 7922-37.

Canuel R, de Grosbois SB, Atikesse L, Lucotte M, Arp P, Ritchie C, Mergler D, Chan HM, Amyot M, Anderson R. 2006. New evidence on variations of human body burden of methylmercury from fish consumption. Environ Health Perspect. 114: 302-306.

Carneiro MF, Grotto D, Barbosa F Jr. 2014. Inorganic and methylmercury levels in plasma are differentially associated with age, gender, and oxidative stress markers in a population exposed to mercury through fish consumption. J Toxicol Environ Health A. 77(1-3):69-79.

Carocci A1, Rovito N, Sinicropi MS, Genchi G. Mercury toxicity and neurodegenerative effects. Rev Environ Contam Toxicol. 2014;229:1-18. doi: 10.1007/978-3-319-03777-6_1.

Castilhos, Z. C., et al., 2006. Mercury contamination in fish from gold mining areas in Indonesia and human health risk assessment. Sci Total Environ. 368, 320-5.

Chadambuka, A., et al., 2013. Prevalence of noise induced hearing loss among employees at a mining industry in Zimbabwe. Afr Health Sci. 13, 899-906.

Chan-Hon-Tong, A. et al., 2013. Exposure to food contaminants during pregnancy. The Science of the total environment, 458-460, pp.27-35.

Chan, C. \& Jacobs, R.R., 2013. Analysis of potential mercury policies: the impact of stream basin characteristics on susceptible populations. Integrated environmental assessment and management, 9(1), pp.124-133.

Chen et al, 2012. Thyroid hormones in relation to lead, mercury and cadmium exposure in the National Health and Nutrition Examination Survey, 2007- 2008. Environ Health Perspec 121: 181- 186.

Chen, Z. et al., 2014. Placental transfer and concentrations of cadmium, mercury, lead, and selenium in mothers, newborns, and young children. Journal of exposure science \& environmental epidemiology, 24(5), pp.537-544. 
Choi, A.L., Cordier, S., Weihe, P., Grandjean, P. 2008. Negative confounding in the evaluation of toxicity: the case of methylmercury in fish and seafood. Crit. Rev. Toxicol. 38, 877-893.

Choi AL, Mogensen, UB, Bjerve K., Debes F, Weihe P, Grandjean P, Budtz-Jørgensen E. 2014.

Negative confounding by essential fatty acids in methylmercury neurotoxicity associations. Neurotoxicol. Teratol., 42:85-92.

Choi, B. et al., 2015. Elevated serum ferritin and mercury concentrations are associated with hypertension; analysis of the fourth and fifth Korea national health and nutrition examination survey (KNHANES IV-2, 3, 2008-2009 and V-1, 2010). Environmental toxicology, 30(1), pp.101-108.

Clarkson, T. W., et al., 2003. The toxicology of mercury--current exposures and clinical manifestations. N Engl J Med. 349, 1731-7.

Clarkson, T.W. 1998. Human toxicology of mercury. J. Tr. El. Exp. Med 11, 303-17.

Cohen, J.T., Bellinger, D.C., Shaywitz, B.A. 2005. A quantitative analysis of prenatal methyl mercury exposure and cognitive development. Am. J. Prev. Med. 29, 353-65.

Cordy, P., et al., 2011. Mercury contamination from artisanal gold mining in Antioquia, Colombia: The world's highest per capita mercury pollution. Sci Total Environ. 410-411, 154-60.

Cordy, P., et al., 2013. Characterization, mapping, and mitigation of mercury vapour emissions from artisanal mining gold shops. Environ Res. 125, 82-91.

Counter, S. A., Buchanan, L. H., 2004. Mercury exposure in children: a review. Toxicol Appl Pharmacol. 198, 209-30.

Crump KS, Kjellstrom T, Shipp AM, Silvers A, Stewart A. Influence of prenatal mercury exposure upon scholastic and psychological test performance: benchmark analysis of a New Zealand cohort. Risk Anal 1998;18(6):701-13.

Custodio HM, Harari R, Gerhardsoon L, Skerfving S, Broberg K. 2005. Genetic influences on the retention of inorganic mercury. Arch Environ Occup Health 60:17-23.

Daniels JL, Longnecker MP, Rowland AS, Golding J, Health ASTUoBIoC. Fish intake during pregnancy and early cognitive development of offspring. Epidemiology 2004;15(4):394402.

Davidson PW, Cory-Slechta DA, Thurston SW, Huang LS, Shamlaye CF, Gunzler D, Watson G, van Wijngaarden E, Zareba G, Klein JD et al. Fish consumption and prenatal methylmercury exposure: cognitive and behavioral outcomes in the main cohort at 17 years from the Seychelles child development study. Neurotoxicology 2011;32(6):711-7.

Davidson PW, Myers GJ, Cox C, Axtell C, Shamlaye C, Sloane-Reeves J, Cernichiari E, Needham L, Choi A, Wang Y et al. Effects of prenatal and postnatal methylmercury exposure from fish consumption on neurodevelopment: outcomes at 66 months of age in the Seychelles Child Development Study. JAMA 1998;280(8):701-7.

Davidson PW, Strain JJ, Myers GJ, Thurston SW, Bonham MP, Shamlaye CF, Stokes-Riner A, Wallace JM, Robson PJ, Duffy EM et al. Neurodevelopmental effects of maternal nutritional status and exposure to methylmercury from eating fish during pregnancy. Neurotoxicology 2008;29(5):767-75.

De Miguel, E., et al., 2014. Probabilistic meta-analysis of risk from the exposure to Hg in artisanal gold mining communities in Colombia. Chemosphere. 108, 183-9.

Debes F, Weihe P, Grandjean P. Cognitive deficits at age 22 years associated with prenatal exposure to methylmercury. Cortex. 2016 Jan;74:358-69. doi: 10.1016/j.cortex.2015.05.017. Epub 2015 Jun 4.

Delgado-Alvarez, C.G. et al., 2015. Mercury content and their risk assessment in farmed shrimp 
Litopenaeus vannamei from NW Mexico. Chemosphere, 119, pp.1015-1020.

Deng et al., 2012 Y. Deng, Z. Xu, W. Liu, H. Yang, B. Xu, Y. Wei Effects of lycopene and proanthocyanidins on hepatotoxicity induced by mercuric chloride in rats Biol. Trace Elem. Res., 146 (2012), pp. 213-223

Deroma, L. et al., 2013. Neuropsychological assessment at school-age and prenatal low-level exposure to mercury through fish consumption in an Italian birth cohort living near a contaminated site. International journal of hygiene and environmental health, 216(4), pp.486-493.

Diringer, S. E., et al., 2015. River transport of mercury from artisanal and small-scale gold mining and risks for dietary mercury exposure in Madre de Dios, Peru. Environ Sci Process Impacts. 17, 478-87.

Donato, D. B., et al., 2007. A critical review of the effects of gold cyanide-bearing tailings solutions on wildlife. Environ Int. 33, 974-84.

Dooyema, C. A. e. a., 2010. Outbreak of Fatal Childhood Lead Poisoning Related to Artisanal Gold Mining in Northwestern Nigeria. Environ Health Perspect. 120, 601-607.

Dórea, J. G., 2004. Mercury and lead during breast-feeding. Br J Nutr. 92, 21-40.

Dórea, J. G., 2008. Community-directed risk assessment of mercury exposure: gold mining, fish, and unsuspected ethylmercury. Rev Panam Salud Publica. 24, 220-1; author reply 221-2.

Dórea, J. G., 2014. Chemical mixtures, maternal exposure and infant neurodevelopment: did we miss positive (breastfeeding) and negative (mercury) confounders? Neurotoxicol Teratol. 45, 93.

Dórea, J.G. 2015. Exposure to mercury and aluminum in early life: developmental vulnerability as a modifying factor in neurologic and immunologic effects. Int J Environ Res. Public Health $12,1295-313$.

Dórea, J.G., Souza, J.R., Rodrigues, P., Ferrari, I., Barbosa, A.C. 2005. Hair mercury (signature of fish consumption) and cardiovascular risk in Munduruku and Kayabi Indians of Amazonia. Environ. Res. 97, 209-19.

Drasch, G., et al., 2001. The Mt. Diwata study on the Philippines 1999--assessing mercury intoxication of the population by small scale gold mining. Sci Total Environ. 267, 151-68.

Drasch, G., et al., Mercury. In: E. Merian, et al., Eds.), Elements and their Compounds in the Environment. Wiley-VHC Verlag, Weinheim, Germany, 2004, pp. 931 - 1005.

Driscoll, C.T. et al., 2013. Mercury as a global pollutant: Sources, pathways, and effects. Environmental science \& technology, 47(10), pp.4967-4983.

Echeverria D, Woods JS, Heyer NJ, Martin MD, Rohlman DS, Farin FM, Tingting L. 2010. The association between serotonin transporter gene promotor polymorphism (5-HTTLPR) and elemental mercury exposure on mood and behavior in humans. $J$ Toxicol Environ Health A 73:1003-1020.

Echeverria D, Woods JS, Heyer NJ, Martin MD, Rohlman DS, Farin FM, Tingting L. 2010. The association between serotonin transporter gene promotor polymorphism (5-HTTLPR) and elemental mercury exposure on mood and behavior in humans. J Toxicol Environ Health A 73:1003-1020.

Echeverria D, Woods JS, Heyer NJ, Rohlman D, Farin FM, Bittner AC, Tingting L, Garabedian CE. 2005. Chronic low-level mercury exposure, BDNF polymorphism, and associations with cognitive and motor function. Neurotoxicol Teratol 27:781-796.

Echeverria D, Woods JS, Heyer NJ, Rohlman D, Farin FM, Li T, Garabedian CE. 2006. The assocation between a genetic polymorphism of coproporphyrinogen oxidase, dental 
mercury exposure and neurobehavioral response in humans. Neurotoxicol Teratol 28:3948.

EFSA Scientific Committee, 2015. Statement on the benefits of fish / seafood consumption compared to the risks of methylmercury in fish / seafood. EFSA Journal, 13(1), p.3982.

Ekino, S. et al., 2007. Minamata disease revisited: an update on the acute and chronic manifestations of methyl mercury poisoning. Journal of the neurological sciences, 262(12), pp.131-44. Available at: http://www.ncbi.nlm.nih.gov/pubmed/17681548 [Accessed July 19, 2012].

Engstrom K, Ameer S, Bernaudat L, Drasch G, Baeuml J, Skerfving S, Bose-O'Reilly S, Broberg K. 2013. Polymorphisms in genes encoding potential mercury transporters and urine mercury concentrations in populations exposed to mercury vapor from gold mining. Environ Health Perspect 121:85-91.

Environ Health Perspect. 2012 Jun;120(6):799-806. doi: 10.1289/ehp.1104494. Epub 2012 Jan 24. Review.

Eom, S.-Y. et al., 2014. Reference levels of blood mercury and association with metabolic syndrome in Korean adults. International archives of occupational and environmental health, 87(5), pp.501-513.

FAO/WHO, 2011. Report of the JOINT FAO / WHO EXPERT CONSULTATION ON THE RISKS AND BENEFITS OF FISH CONSUMPTION, Rome.

Farina M, Rocha JB, Aschner M. 2011. Mechanisms of methylmercury-induce neurotoxicity: evidence from experimental studies. Life Sci. 89 (15-16):555-63.

Feng, X., et al., 2008. Human exposure to methylmercury through rice intake in mercury mining areas, Guizhou province, China. Environ Sci Technol. 42, 326-32.

Fillion, M. et al., 2013. Toxic risks and nutritional benefits of traditional diet on near visual contrast sensitivity and color vision in the Brazilian Amazon. Neurotoxicology, 37, pp.173-181.

Fillion, M., Mergler, D., Sousa Passos, C.J, Larribe, F., Lemire, M., Guimarães, J.R.A. 2006. A preliminary study of mercury exposure and blood pressure in the Brazilian Amazon. Environ. Health 5, 29.

Fox, D.A. et al., 2012. Developmental origins of adult diseases and neurotoxicity: epidemiological and experimental studies. Neurotoxicology, 33(4), pp.810-816.

Frery, N., et al., 2001. Gold-mining activities and mercury contamination of native amerindian communities in French Guiana: key role of fish in dietary uptake. Environ Health Perspect. 109, 449-56.

Gagné D, Lauzière J, Blanchet R, Vézina C, Vaissière E, Ayotte P, Turgeon O'Brien H.Consumption of tomato products is associated with lower blood mercury levels in Inuit preschool children. Food Chem Toxicol. 2013 Jan;51:404-10. doi: 10.1016/j.fct.2012.10.031. Epub 2012 Nov 2.

Garcia-Esquinas, E. et al., 2013. Lead, mercury and cadmium in umbilical cord blood and its association with parental epidemiological variables and birth factors. BMC public health, 13, p.841.

Geer, L.A. et al., 2012. Assessment of prenatal mercury exposure in a predominately Caribbean immigrant community in Brooklyn, NY. Journal of environmental monitoring : JEM, 14(3), pp.1035-1043.

Geier, D.A. et al., 2012. Hair toxic metal concentrations and autism spectrum disorder severity in young children. International journal of environmental research and public health, 9(12), pp.4486-4497. 
Geier, D.A., Kern, J.K., Hooker, B.S., King, P.G., Sykes, L.K., Geier, M.R. 2015. A longitudinal cohort study of the relationship between Thimerosal-containing hepatitis B vaccination and specific delays in development in the United States: Assessment of attributable risk and lifetime care costs. J. Epidemiol. Glob. Health. pii: S2210-6006(15)00064-7. doi: 10.1016/j.jegh.2015.06.002

Gibb, H., O'Leary, K. G., 2014. Mercury Exposure and Health Impacts among Individuals in the Artisanal and Small-Scale Gold Mining Community: A Comprehensive Review. Environ Health Perspect.

Golding J, Steer CD, Hibbeln JR, Emmett PM, Lowery T, Jones R. Dietary predictors of maternal prenatal blood mercury levels in the ALSPAC birth cohort study. Environ Health Perspect. 2013 Oct;121(10):1214-8. doi: 10.1289/ehp.1206115. Epub 2013 Jun 28.

Gonzalez-Carrasco, V., et al., 2011. Air mercury contamination in the gold mining town of Portovelo, Ecuador. Bull Environ Contam Toxicol. 87, 250-3.

Goodrich J, Basu N, Franzblau A, Dolinoy D. 2013. Mercury biomarkers and DNA methylation among Michigan Dental Professionals. Environ Mol Mutag. 54: 195-203.

Goodrich, J., Wang, Y., Gillespie, B., Werner, R., Franzblau, A., Basu, N. 2011. Glutathione enzyme and selenoprotein polymorphisms affect mercury biomarker levels in Michigan dental professionals. Toxicology and Applied Pharmacology. 257(2): 301-308

Goodrich, J.M., Chou, H-N., Gruninger, S., Franzblau, A., Basu, N. 2016. Exposures of Dental Professionals to Elemental Mercury and Methylmercury. Journal of Exposure Science and Environmental Epidemiology. 26: 78-85.

Grandjean P, Weihe P, White RF, Debes F, Araki S, Yokoyama K, Murata K, Sorensen N, Dahl R, Jorgensen PJ. Cognitive deficit in 7-year-old children with prenatal exposure to methylmercury. Neurotoxicol Teratol 1997;19(6):417-28.

Grandjean, P. \& Landrigan, P.J., 2014. Neurobehavioural effects of developmental toxicity. The Lancet. Neurology, 13(3), pp.330-338.

Grandjean, P. et al., 2010. Adverse effects of methylmercury: environmental health research implications. Environmental health perspectives, 118(8), pp.1137-45. Available at: http://www.pubmedcentral.nih.gov/articlerender.fcgi? artid=2920086\&tool=pmcentrez\&rendertype=abstract [Accessed March 19, 2012].

Grandjean, P. et al., 2012. Neurobehavioral deficits at age 7 years associated with prenatal exposure to toxicants from maternal seafood diet. Neurotoxicology and teratology, 34(4), pp.466472.

Grandjean, P., 2007. Methylmercury toxicity and functional programming. Reprod Toxicol. 23, 41420.

Grandjean, P., et al., 1999. Methylmercury neurotoxicity in Amazonian children downstream from gold mining. Environ Health Perspect. 107, 587-91.

Grandjean, P., et al., 2014. Neurotoxicity from prenatal and postnatal exposure to methylmercury. Neurotoxicol Teratol. 43, 39-44.

Grandjean, P., Landrigan, P. J., 2014. Neurobehavioural effects of developmental toxicity. Lancet Neurol. 13, 330-338.

Greig, J., et al., 2014. Association of Blood Lead Level with Neurological Features in 972 Children Affected by an Acute Severe Lead Poisoning Outbreak in Zamfara State, Northern Nigeria. PLoS ONE. 9, e93716. 
Guallar, E., Sanz-Gallardo, M.I., van't Veer, P., Bode, P., Aro, A., Gomez-Aracena, J., et al. 2002. Heavy metals and myocardial infarction study group: mercury, fish oils, and the risk of myocardial infarction. N. Engl. J. Med. 347, 1747-54.

Gundacker C, Komarnick G, Jagiello P, Gencikova A, Dahmen N, Wittmann KJ, Gencik M. 2007. Glutathione s-transferase polymorphism, metallothionein expression, and mercury levels among students in Austria. Sci Total Environ 385:37-47.

Gundacker C, Wittmann KJ, Kukuckova M, Komarnicki G, Hikkel I, Gencik M. 2009. Genetic background of lead and mercury metabolism in a group of medical students in Austria. Environ Res 109:786-796.

Hamann, C.R. et al., 2014. Spectrometric analysis of mercury content in 549 skin-lightening products: is mercury toxicity a hidden global health hazard? Journal of the American Academy of Dermatology, 70(2), pp.281-7.e3.

Hanna CW, Bloom MS, Robinson WP, Kim D, Parsons PJ, vom Saal FS, Taylor JA, Steuerwald AJ, Fujimoto VY. 2012. DNA methylation changes in whole blood is associated with exposure to the environmental contaminants, mercury, lead, cadmium and bisphenol A, in women undergoing ovarian stimulation for IVF. Hum Reprod 27:1401-10.

Harada, M., 1995. Minamata disease: methylmercury poisoning in Japan caused by environmental pollution. Critical reviews in toxicology, 25(1), pp.1-24. Available at: http://www.ncbi.nlm.nih.gov/pubmed/7734058.

Harada, M. 1982. Minamata disease. Mercury poisoning caused by ingestion of contaminated fish. In: Jelliffe, E.F.P., Jelliffe, D.B., editors. Adverse Effects of Food. Plenum Publishing Co. p. 135-48.

Harari R, Harari F, Gerhardsson L, Lundh T, Skerfving S, Stromberg U, Broberg K. 2012. Exposure and toxic effects of elemental mercury in gold-mining activities in Ecuador. Toxicol Lett 213:75-82.

He, K. et al., 2013. Mercury exposure in young adulthood and incidence of diabetes later in life: the CARDIA Trace Element Study. Diabetes care, 36(6), pp.1584-1589.

Head JA, Dolinoy DC, Basu N. 2012. An Introduction to Epigenetics for Ecotoxicologists. Environ Toxicol Chem. 31:221-227.

Hébert JR, Hurley TG, Steck SE, Miller DR, Tabung FK, Peterson KE, Kushi LH, Frongillo EA. 2014. Considering the value of dietary assessment data in informing nutrition-related health policy. Adv Nutr. 5(4):447-55.

Hentschel, T., et al., 2002. Global Report on Artisanal \& Small-Scale Mining.

Heyer NJ, Echeverria D, Bittner AC,Jr, Farin FM, Garabedian CC, Woods JS. 2004. Chronic lowlevel mercury exposure, BDNF polymorphism, and associations with self-reported symptoms and mood. Toxicol Sci 81:354-363.

Hruba, F., et al., 2012. Blood cadmium, mercury, and lead in children: an international comparison of cities in six European countries, and China, Ecuador, and Morocco. Environ Int. 41, 2934.

Jadán-Piedra, C. et al., 2016. Influence of Physiological Gastrointestinal Parameters on the Bioaccessibility of Mercury and Selenium from Swordfish. Journal of agricultural and food chemistry. Available at: http://www.ncbi.nlm.nih.gov/pubmed/26726738 [Accessed January 25, 2016].

Jo S, Woo HD, Kwon HJ, et al. 2015. Estimation of the Biological Half-Life of Methylmercury Using a Population Toxicokinetic Model. Int J Environ Res Public Health. 12(8):9054-67. Jin, L. et al., 2013. Placental concentrations of mercury, lead, cadmium, and arsenic and the risk of 
neural tube defects in a Chinese population. Reproductive toxicology (EImsford, N.Y.), 35, pp.25-31.

Julvez, J. et al., 2013. Prenatal methylmercury exposure and genetic predisposition to cognitive deficit at age 8 years. Epidemiology (Cambridge, Mass.), 24(5), pp.643-650.

Kalish, B.T. et al., 2014. Associations of prenatal maternal blood mercury concentrations with early and mid-childhood blood pressure: a prospective study. Environmental research, 133, pp.327-333.

Karagas MR, Choi AL, Oken E, Horvat M, Schoeny R, Kamai E, Cowell W, Grandjean P, Korrick S. 2012. Evidence on the human health effects of low-level methylmercury exposure. Environ Health Perspect.120(6):, (6), pp.799-806.

King, E. et al., 2013. Mercury, lead, and cadmium in umbilical cord blood. Journal of environmental health, 75(6), pp.38-43.

Kippenberg, J., 2011. A Poisonous Mix - Child Labor, Mercury, and Artisanal Gold Mining in Mali USA.

Koos BJ, Longo LD. 1976. Mercury toxicity in the pregnant woman, fetus, and newborn infant. A review. Am. J. Obstet. Gynecol. 126, 390-409.

Krisnayanti, B. D., et al., 2012. Assessment of environmental mercury discharge at a four-year-old artisanal gold mining area on Lombok Island, Indonesia. J Environ Monit. 14, 2598-607.

Kristensen, A. K., et al., 2013. A review of mercury exposure among artisanal small-scale gold miners in developing countries. Int Arch Occup Environ Health.

Kuratko CN, Barrett EC, Nelson EB, Salem N Jr. The relationship of docosahexaenoic acid (DHA) with learning and behavior in healthy children: a review. Nutrients. 2013 Jul 19;5(7):2777810. doi: 10.3390/nu5072777. Review.

Kurland, T., Faro, S.N. \& Siedler, H., 1960. Minamata disease. The outbreak of a neurologic disorder in Minamata, Japan, and its relationship to the ingestion of seafood contaminated by mercuric compounds. World neurology, 1(5), pp.370-395.

Laird, B.D. et al., 2013. Dietary advice on Inuit traditional food use needs to balance benefits and risks of mercury, selenium, and n3 fatty acids. The Journal of nutrition, 143(6), pp.923930.

Lee B, Hong Y, Park H, Ha M, Koo BS, Chang N, Roh Y, Kim B, Kim Y, Kim B, Jo S, Ha E. 2010. Interaction between GSTM1/GSTT1 polymorphism and blood mercury on birth weight. Environ Health Perspect 118:437-443.

Lettmeier, B., et al., 2010. Proposal for a revised Reference Concentration (RfC) for mercury vapour in adults. Sci Total Environ. 408, 3530-3535.

Li M, Sherman LS, Blum JD, Grandjean P, Mikkelsen B, Weihe P, Sunderland EM, Shine JP. Assessing sources of human methylmercury exposure using stable mercury isotopes. Environ Sci Technol. 2014;48(15):8800-6.

Li, P. et al., 2012. Rice consumption contributes to low level methylmercury exposure in southern China. Environment international, 49, pp.18-23.

Li, P., et al., 2015. Human Body Burden and Dietary Methylmercury Intake: The Relationship in a Rice-Consuming Population. Environ Sci Technol. 49, 9682-9.

Li, W.C., Ouyang, Y. \& Ye, Z.H., 2014. Accumulation of mercury and cadmium in rice from paddy soil near a mercury mine. Environmental toxicology and chemistry / SETAC, 33(11), pp.2438-2447.

Liberda, E.N. et al., 2014. The complexity of hair/blood mercury concentration ratios and its implications. Environmental research, 134, pp.286-294. 
Lin Y, Vogt R, Larssen T. Environmental mercury in China: a review. Environ Toxicol Chem. 2012 Nov;31(11):2431-44. doi: 10.1002/etc.1980. Epub 2012 Aug 29. Review.

Lkhasuren, O., et al., 2007. Occupational lung diseases and the mining industry in Mongolia. Int J Occup Environ Health. 13, 195-201.

Llop S, Ballester F, Broberg K. 2015. Effect of Gene-Mercury Interactions on Mercury Toxicokinetics and Neurotoxicity. Curr Environ Health Rep. 2(2):179-94.

Llop, S. et al., 2012. Prenatal exposure to mercury and infant neurodevelopment in a multicenter cohort in Spain: study of potential modifiers. American journal of epidemiology, 175(5), pp.451-465.

Lunder S. 2016. U.S .Fish Advice may expose babies to too much mercury. Available: http://www.ewg.org/research/us-fish-advice-may-expose-babies-too-much-mercury

Magos L, Clarkson TW. Overview of the clinical toxicity of mercury. Ann Clin Biochem. 2006 Jul;43(Pt 4):257-68. Review.

Marques, R.C. et al., 2013. Fish consumption during pregnancy, mercury transfer, and birth weight along the Madeira River Basin in Amazonia. International journal of environmental research and public health, 10(6), pp.2150-2163.

Marques, R.C., Abreu, L., Bernardi, J.V., Dórea, J.G. 2016. Neurodevelopment of Amazonian children exposed to ethylmercury (from Thimerosal in vaccines) and methylmercury (from fish). Environ Res. 2016 Jan 7. pii: S0013-9351(15)30184-5. doi:10.1016/j.envres.2015.12.022.

Matos, J. et al., 2015. Influence of bioaccessibility of total mercury, methyl-mercury and selenium on the risk/benefit associated to the consumption of raw and cooked blue shark (Prionace glauca). Environmental research, 143(Pt B), pp.123-9. Available at: http://www.ncbi.nlm.nih.gov/pubmed/26409850 [Accessed January 25, 2016].

Meng B, Feng X, Qiu G, Anderson CW, Wang J, Zhao L. Localization and speciation of mercury in brown rice with implications for pan-Asian public health. Environ Sci Technol. 2014 Jul 15;48(14):7974-81. doi: 10.1021/es502000d. Epub 2014 Jun 23.

Mergler, D. et al., 2007. Methylmercury exposure and health effects in humans: a worldwide concern. Ambio, 36(1), pp.3-11. Available at: http://www.ncbi.nlm.nih.gov/pubmed/17408186.

Mutter, J. \& Yeter, D., 2008. Kawasaki’s disease, acrodynia, and mercury. Current medicinal chemistry, 15(28), pp.3000-10. Available at: http://www.ncbi.nlm.nih.gov/pubmed/19075648.

Myers GJ, Davidson PW, Cox C, Shamlaye CF, Palumbo D, Cernichiari E, Sloane-Reeves J, Wilding GE, Kost J, Huang LS et al. Prenatal methylmercury exposure from ocean fish consumption in the Seychelles child development study. Lancet 2003;361(9370):1686-92.

Myers, G. J., et al., 1995. Neurodevelopmental outcomes of Seychellois children sixty-six months after in utero exposure to methylmercury from a maternal fish diet: pilot study. Neurotoxicology. 16, 639-52.

Myers, G.J. et al., 2015. Methylmercury exposure and developmental neurotoxicity. Bulletin of the World Health Organization, 93(2), p.132A-132B.

Nakamura, M. et al., 2014. Methylmercury exposure and neurological outcomes in Taiji residents accustomed to consuming whale meat. Environment international, 68, pp.25-32.

Nesheim, M.C. \& Nestle, M., 2014. Advice for fish consumption: challenging dilemmas. The American journal of clinical nutrition, 99(5), pp.973-974. 
Niane, B., et al., 2015. Human exposure to mercury in artisanal small-scale gold mining areas of Kedougou region, Senegal, as a function of occupational activity and fish consumption. Environ Sci Pollut Res Int. 22, 7101-11.

Obiri, S., et al., 2006. Non-cancer health risk assessment from exposure to cyanide by resident adults from the mining operations of Bogoso Gold Limited in Ghana. Environ Monit Assess. 118, 51-63. Ohlander, J., et al., 2013. Risk factors for mercury exposure of children in a rural mining town in northern Chile. PLoS One. 8, e79756.

Oken E et al. 2008. Maternal fish intake during pregnancy, blood mercury levels, and child cognition at age 3 years in a US cohort. American Journal of Epidemiology. 167, 11711181.

Ono, F. B., et al., 2012. Arsenic bioaccessibility in a gold mining area: a health risk assessment for children. Environ Geochem Health. 34, 457-65.

Parajuli RP, Goodrich JM, Chou HN, Gruninger SE, Dolinoy DC, Franzblau A, Basu N. 2016. Genetic polymorphisms are associated with hair, blood, and urine mercury levels in the American Dental Association (ADA) study participants. Environ Res. S00139351(15)30160-2. doi: 10.1016/j.envres.2015.11.032. [Epub ahead of print] PubMed PMID: 26673400.

Park, J.-H. et al., 2014. Total mercury concentrations in the general Korean population, 2008-2011. Regulatory toxicology and pharmacology : RTP, 70(3), pp.681-686.

Park, S.K. et al., 2013. Associations of blood and urinary mercury with hypertension in U.S. adults: the NHANES 2003-2006. Environmental research, 123, pp.25-32.

Passos CJ, Mergler D, Fillion M, Lemire M, Mertens F, Guimarães JR, Philibert A. Epidemiologic confirmation that fruit consumption influences mercury exposure in riparian communities in the Brazilian Amazon. Environ Res. 2007 Oct;105(2):183-93. Epub 2007 Mar 19.

Pearce EN. 2013. Monitoring and effects of iodine deficiency in pregnancy: still an unsolved problem? Eur J Clin Nutr. 67(5):481-4.

Peplow, D. \& Augustine, S., 2012. Community-led assessment of risk from exposure to mercury by native Amerindian Wayana in Southeast Suriname. Journal of environmental and public health, 2012, p.674596.

Philippe G, et al. 2012. Calculation of Mercury's Effects on Neurodevelopment. Environmental Health Perspectives. 120:a450-a452. Available: www.ncbi. nlm.nih.gov/pmc/articles/PMC3548290/

Pilsner JR, Lazarus AL, Nam DH, Letcher RJ, Sonne C, Dietz R, Basu N. 2010. Mercury-associated DNA hypomethylation in polar bear brains via the LUminometric Methylation Assay: a sensitive method to study epigenetics in wildlife. Mol Ecol 19:307-314.

Polanska, K. et al., 2013. Developmental effects of exposures to environmental factors: the Polish Mother and Child Cohort Study. BioMed research international, 2013, p.629716.

Rajaee M, Long RN, Renne EP, Basu N. 2015. Mercury Exposure Assessment and Spatial Distribution in A Ghanaian Small-Scale Gold Mining Community. Int J Environ Res Public Health. 12(9):10755-82.

Rand, M.D. et al., 2015. Methods for Individualized Determination of Methylmercury Elimination Rate and De-Methylation Status in Humans Following Fish Consumption.

Toxicological sciences : an official journal of the Society of Toxicology. Available at:

http://www.ncbi.nlm.nih.gov/pubmed/26572661 [Accessed January 21, 2016].

Rayman MP. 2012. Selenium and human health. Lancet. 379(9822):1256-68. 
Rymond LJ, Ralston NVC. 2009. Selenium's importance in regulatory issues regarding mercury Fuel Processing Technology, 90(11):1333-1338.

Rheinberger, C.M. \& Hammitt, J.K., 2012. Risk trade-offs in fish consumption: a public health perspective. Environmental science \& technology, 46(22), pp.12337-12346.

Rice, K.M. et al., 2014. Environmental mercury and its toxic effects. Journal of preventive medicine and public health = Yebang Uihakhoe chi, 47(2), pp.74-83.

Roman, H. a et al., 2011. Evaluation of the cardiovascular effects of methylmercury exposures: current evidence supports development of a dose-response function for regulatory benefits analysis. Environmental health perspectives, 119(5), pp.607-14.

Rooney, J.P. 2014. The retention time of inorganic mercury in the brain--a systematic review of the evidence. Toxicol Appl Pharmacol. 274, 425, 435.

Rothenberg SE, Keiser S, Ajami NJ, Wong MC, Gesell J, Petrosino JF, Johs A. 2016. The role of gut microbiota in fetal methylmercury exposure: Insights from a pilot study. Toxicol Lett. 242:60-7.

Rothenberg, S. E., et al., 2014. Rice methylmercury exposure and mitigation: a comprehensive review. Environ Res. 133, 407-23.

Sagiv, S.K. et al., 2012. Prenatal exposure to mercury and fish consumption during pregnancy and attention-deficit/hyperactivity disorder-related behavior in children. Archives of pediatrics \& adolescent medicine, 166(12), pp.1123-1131.

Sakamoto, M. et al., 2012. Can umbilical cord be used as a predictor of prenatal exposure to heavy metals? Toxicology Letters, 211, pp.S145-S146.

Sakamoto, M.; Chan, H.M.; Domingo, J.L.; Oliveira, R.B.; Kawakami, S.; Murata, K. Significance of fingernail and toenail mercury concentrations as biomarkers for prenatal methylmercury exposure in relation to segmental hair mercury concentrations. Environ Res. 136:289-294; 2015

Ser, P.H. \& Watanabe, C., 2012. Fish advisories in the USA and Japan: risk communication and public awareness of a common idea with different backgrounds. Asia Pacific journal of clinical nutrition, 21(4), pp.487-494.

Sheehan, M.C. et al., 2014. Global methylmercury exposure from seafood consumption and risk of developmental neurotoxicity: a systematic review. Bulletin of the World Health Organization, 92(4), pp.254-269F.

Sherman, L., Blum, J.D., Franzblau, A, Basu, N. 2013. New insight into biomarkers of human mercury exposure using naturally occurring mercury stable isotopes. Environmental Science and Technology. 47: 3403-3409.

Sherman, L.S., Blum, J.D., Basu, N., Rajaee, M., Evers, D.C., Buck, D.G., Petrlik, J., DiGangi, J. 2015. Assessment of mercury exposure amongst small-scale gold miners using mercury stable isotopes. Environmental Research. 137: 226-234

Silva de Paula E, Carneiro MF, Grotto D, Hernandes LC, Antunes LM, Barbosa F Jr. 2016. Protective effects of niacin against methylmercury-induced genotoxicity and alterations in antioxidant status in rats J. Tox. Environ. Health, Part A, DOI $10.1080 / 15287394.2015 .1137264$

Steenweg-de Graaff, J. Tiemeier H, Ghassabian A, Rijlaarsdam J, Jaddoe VWV, Verhulst FC, and Roza SJ. 2016. Maternal Fatty Acid Status During Pregnancy and Child Autistic Traits: The Generation R Study. Am. J. Epidemiol. 183: 792-799.

Skeaff, 2011. Iodine Deficiency in Pregnancy: The Effect on Neurodevelopment in the Child. Nutrients 3: 265-276. 
Smolders, R. et al., 2015. Interpreting biomarker data from the COPHES/DEMOCOPHES twin projects: Using external exposure data to understand biomarker differences among countries. Environmental research, 141, pp.86-95.

Spiegel, S. J., et al., 2005. Reducing mercury and responding to the global gold rush. Lancet. 366, 2070-2.

Steckling, N., et al., 2011. Mercury exposure in female artisanal small-scale gold miners (ASGM) in Mongolia: An analysis of human biomonitoring (HBM) data from 2008. Sci Total Environ. 409, 994-1000.

Steckling, N., et al., 2014. The burden of chronic mercury intoxication in artisanal small-scale gold mining in Zimbabwe: data availability and preliminary estimates. Environ Health. 13, 111.

Steckling, N., et al., 2015. Disease profile and health-related quality of life (HRQoL) using the EuroQol (EQ-5D + C) questionnaire for chronic metallic mercury vapor intoxication. Health Qual Life Outcomes. 13, 196.

Strain JJ, Davidson PW, Bonham MP, Duffy EM, Stokes-Riner A, Thurston SW, Wallace JM, Robson PJ, Shamlaye CF, Georger LA et al. 2008. Associations of maternal long-chain polyunsaturated fatty acids, methyl mercury, and infant development in the Seychelles Child Development Nutrition Study. Neurotoxicology 29(5):776-82.

Strain JJ, Davidson PW, Thurston SW, Harrington D, Mulhern MS, McAfee AJ, van Wijngaarden E, Shamlaye CF, Henderson J, Watson GE et al. 2012. Maternal PUFA status but not prenatal methylmercury exposure is associated with children's language functions at age five years in the Seychelles. J Nutr 142(11):1943-9.

Strain JJ, Yeates AJ, van Wijngaarden E, Thurston SW, Mulhern MS, McSorley EM, Watson GE, Love TM, Smith TH, Yost K, Harrington D, Shamlaye CF, Henderson J, Myers GJ, Davidson PW. 2015. Prenatal exposure to methyl mercury from fish consumption and polyunsaturated fatty acids: associations with child development at 20 mo of age in an observational study in the Republic of Seychelles. Am J Clin Nutr. 101(3):530-7.

Sunderland, E.M. \& Selin, N.E., 2013. Future trends in environmental mercury concentrations: implications for prevention strategies. Environmental Health, 12, p.2.

Sunderland, E.M. \& Selin, N.E., 2013. Future trends in environmental mercury concentrations: implications for prevention strategies. Environmental health : a global access science source, 12, p.2.

Sunderland, E.M. et al., 2009. Mercury sources, distribution, and bioavailability in the North Pacific Ocean: Insights from data and models. Global Biogeochemical Cycles, 23(2), pp.1-14. Available at: http://www.agu.org/pubs/crossref/2009/2008GB003425.shtml [Accessed November 6, 2011].

Syversen, T. \& Kaur, P., 2012. The toxicology of mercury and its compounds. Journal of trace elements in medicine and biology: organ of the Society for Minerals and Trace Elements (GMS), 26(4), pp.215-226.

Tatsuta, N. et al., 2012. Prenatal exposures to environmental chemicals and birth order as risk factors for child behavior problems. Environmental research, 114, pp.47-52. Available at: http://www.ncbi.nlm.nih.gov/pubmed/22421256 [Accessed August 27, 2012].

Tatsuta, N. et al., 2014. Impacts of prenatal exposures to polychlorinated biphenyls, methylmercury, and lead on intellectual ability of 42-month-old children in Japan. Environmental research, 133, pp.321-326.

Teisl MF, Fromberg E, Smith AE, Boyle KJ, Engelberth HM. 2011. Awake at the switch: improving fish consumption advisories for at-risk women. Sci Total Environ 409:3257-3266 
Thapa, D.S. et al., 2014. The risk of mercury exposure to the people consuming fish from Lake Phewa, Nepal. International journal of environmental research and public health, 11(7), pp.6771-6779.

Thomas, S. et al., 2015. Metals exposure and risk of small-for-gestational age birth in a Canadian birth cohort: The MIREC study. Environmental research, 140, pp.430-439.

Traynor, S. et al., 2013. Fish consumption patterns and mercury exposure levels among women of childbearing age in Duval County, Florida. Journal of environmental health, 75(6), pp.815.

UNEP, 2008. The global atmospheric mercury assessment: souces, emission, transport. : Geneva: UNEP Chemical Branch.

UNEP, 2013a. Global Mercury Assessment 2013: Sources, Emissions, Releases, and Environmental Transport. UNEP, p.42.

UNEP, 2013b. Minamata Convention on mercury. Text and Annexes. From:

(http://www.mercuryconvention.org/Portals/11/documents/Booklets/Minamata\%20Convention

\%20on\%20Mercury booklet English.pdf)

UNIDO, 2008. Protocols for environmental and health assessment of mercury released by artisanal and small-scale gold miners.

Ushijima, K. et al., 2012. Association between early methylmercury exposure and functional health among residents of the Shiranui Sea communities in Japan. International journal of environmental health research, 22(5), pp.387-400.

van Wijngaarden, E. et al., 2013. Autism spectrum disorder phenotypes and prenatal exposure to methylmercury. Epidemiology (Cambridge, Mass.), 24(5), pp.651-659.

Veiga, M.M., Maxson, P. a. \& Hylander, L.D., 2006. Origin and consumption of mercury in smallscale gold mining. Journal of Cleaner Production, 14, pp.436-447.

Veyhe, A.S. et al., 2015. The Northern Norway Mother-and-Child Contaminant Cohort (MISA) Study: PCA analyses of environmental contaminants in maternal sera and dietary intake in early pregnancy. International journal of hygiene and environmental health, 218(2), pp.254-264.

Liu, W. Z. Xu, Y. Deng, B. Xu, H. Yang, Y. Wei, et al. 2014. Excitotoxicity and oxidative damages induced by methylmercury in rat cerebral cortex and the protective effects of tea polyphenols Environ. Toxicol. 29:269-283.

Wade, L., 2013. Mercury pollution. Gold's dark side. Science. 341, 1448-9.

Wang, H.-S. et al., 2013. In vitro estimation of exposure of Hong Kong residents to mercury and methylmercury via consumption of market fishes. Journal of hazardous materials, 248249, pp.387-93. Available at: http://www.ncbi.nlm.nih.gov/pubmed/23416482 [Accessed January 25, 2016].

Wang, Y., Goodrich, J.M., Gillespie, B., Werner, R.A., Basu, N., Franzblau, A. 2012.

Metallothionein single nucleotide polymorphisms and changes in urinary and hair mercury levels. Environmental Health Perspectives. 120: 530-534.

Weihe, P. \& Joensen, H.D., 2012. Dietary recommendations regarding pilot whale meat and blubber in the Faroe Islands. International journal of circumpolar health, 71, p.18594.

Wenstrom, K.D., 2014. The FDA's new advice on fish: it's complicated. American journal of obstetrics and gynecology, 211(5), pp.475-478.e1.

WHO, 1976. Mercury. Environmental Health Criteria. No. 1. Available at: http://www.inchem.org/documents/ehc/ehc/ehc001.htm 
WHO, 1990. Methylmercury. Environmental Health Criteria. No. 101. Available at: http://www.inchem.org/documents/ehc/ehc/ehc001.htm

WHO, 2010. GEMS / Food Programme REPORT OF THE WHO WORKING GROUP ON DATA, Geneva. Available at: http://www.who.int/foodsafety/chem/gems/en/index.html.

Woods JS, Echeverria D, Heyer NJ, Simmonds PL, Wilkerson J, Farin FM. 2005. The assocation between genetic polymorpisms of coproporphyrinogen oxidase and an atypical porphryinogenic response to mercury exposure in humans. Toxicol Appl Pharmacol 206:113-120.

Woods JS, Echeverria D, Heyer NJ, Simmonds PL, Wilkerson J, Farin FM. 2005. The assocation between genetic polymorpisms of coproporphyrinogen oxidase and an atypical porphryinogenic response to mercury exposure in humans. Toxicol Appl Pharmacol 206:113-120.

World Health Organization, Mercury Exposure and Health Impacts among Individuals in the Artisanal and Small-Scale Gold Mining (ASGM) Community. Vol. 2014, Geneva, 2013.

Wu, M. et al., 2013. Umbilical cord blood mercury levels in China. Journal of environmental sciences (China), 25(2), pp.386-392.

Yaginuma-sakurai, K. et al., 2012. Hair-to-blood ratio and biological half-life of mercury : experimental study of methylmercury exposure through fish consumption in humans. , 37(1), pp.123-130.

Yang et al., 2012 H. Yang, Z. Xu, W. Liu, Y. Wei, Y. Deng, B. Xu Effect of grape seed proanthocyanidin extracts on methylmercury-induced neurotoxicity in rats Biol. Trace Elem. Res., 147 (2012), pp. 156-164

Yau, V.M. et al., 2014. Prenatal and neonatal peripheral blood mercury levels and autism spectrum disorders. Environmental research, 133, pp.294-303.

Yeter, D. et al., 2016. Ethnic Kawasaki Disease Risk Associated with Blood Mercury and Cadmium in U.S. Children. International journal of environmental research and public health, 13(1). Available at: http://www.ncbi.nlm.nih.gov/pubmed/26742052 [Accessed January 29, 2016].

Yorifuji, T. et al., 2011. Long-term exposure to methylmercury and psychiatric symptoms in residents of Minamata, Japan. Environment international, 37(5), pp.907-13. Available at: http://www.ncbi.nlm.nih.gov/pubmed/21470684 [Accessed April 15, 2012].

You, C.-H. et al., 2014. Relationship between dietary mercury intake and blood mercury level in Korea. Journal of Korean medical science, 29(2), pp.176-182.

Zhang, H. et al., 2014. Total mercury in milled rice and brown rice from China and health risk evaluation. Food additives \& contaminants. Part B, Surveillance, 7(2), pp.141-146. NRC. National Research Council. Toxicological Effects of Methylmercury, Academic Press, Washington, DC. 2000 